\title{
Improving seismotectonics and seismic hazard assessment along the San Ramón Fault at the eastern border of Santiago city, Chile
}

\author{
A. Pérez $\cdot$ J. A. Ruiz $\cdot$ G. Vargas $\cdot$ R. Rauld $\cdot$ S. Rebolledo \\ J. Campos
}

Received: 6 April 2013/Accepted: 22 October 2013/Published online: 21 November 2013

(C) The Author(s) 2013. This article is published with open access at Springerlink.com

\begin{abstract}
The San Ramón Fault is an active west-vergent thrust fault system located along the eastern border of the city of Santiago, at the foot of the main Andes Cordillera. This is a kilometric crustal-scale structure recently recognized that represents a potential source for geological hazards. In this work, we provide new seismological evidences and strong ground-motion modeling from hypothetic kinematic rupture scenarios, to improve seismic hazard assessment in the Metropolitan area of Central Chile. Firstly, we focused on the study of crustal seismicity that we relate to brittle deformation associated with different seismogenic fringes in the main Andes in front of Santiago. We used a classical hypocentral location technique with an improved 1D crustal velocity model, to relocate crustal seismicity recorded between 2000 and 2011 by the National Seismological Service, University of Chile. This analysis includes waveform modeling of seismic events from local broadband stations deployed in the main Andean range, such as San José de Maipo, El Yeso, Las Melosas and Farellones. We selected events located near the stations, whose hypocenters were localized under the recording sites, with angles of incidence at the receiver $<5^{\circ}$ and $\mathrm{S}-\mathrm{P}$ travel times $<2 \mathrm{~s}$. Our results evidence that seismic activity clustered around $10 \mathrm{~km}$ depth under San José de Maipo and Farellones stations. Because of their identical waveforms, such events are interpreted like repeating earthquakes or multiplets and therefore providing first evidence for seismic tectonic activity consistent with the
\end{abstract}

A. Pérez · J. A. Ruiz $(\bowtie) \cdot$ J. Campos

Department of Geophysics, Faculty of Physical and Mathematical Sciences, University of Chile, Blanco Encalada 2002, Santiago, Chile

e-mail: jruiz@dgf.uchile.cl

A. Pérez

e-mail: aperez@dgf.uchile.cl

A. Pérez · G. Vargas · R. Rauld · S. Rebolledo

Department of Geology, Faculty of Physical and Mathematical Sciences, University of Chile, Plaza Ercilla \#803, Santiago, Chile

G. Vargas

Andean Geothermal Center of Excellence, Faculty of Physical and Mathematical Sciences, University of Chile, Plaza Ercilla \#803, Santiago, Chile 
crustal-scale structural model proposed for the San Ramón Fault system in the area (Armijo et al. in Tectonics 29(2):TC2007, 2010). We also analyzed the ground-motion variability generated by an $M_{w} 6.9$ earthquake rupture scenario by using a kinematic fractal $k^{-2}$ composite source model. The main goal was to model broadband strong ground motion in the near-fault region and to analyze the variability of ground-motion parameters computed at various receivers. Several kinematic rupture scenarios were computed by changing physical source parameters. The study focused on statistical analysis of horizontal peak ground acceleration (PGAH) and ground velocity (PGVH). We compared the numerically predicted ground-motion parameters with empirical ground-motion predictive relationships from Kanno et al. (Bull Seismol Soc Am 96:879-897, 2006). In general, the synthetic PGAH and PGVH are in good agreement with the ones empirically predicted at various source distances. However, the mean PGAH at intermediate and large distances attenuates faster than the empirical mean curve. The largest mean values for both, PGAH and PGVH, were observed near the SW corner within the area of the fault plane projected to the surface, which coincides rather well with published hanging-wall effects suggesting that ground motions are amplified there.

Keywords San Ramón Fault · Kinematic rupture scenarios · Ground-motion parameters $\cdot$ Seismotectonics $\cdot$ Seismic hazard $\cdot$ Andes $\cdot$ Santiago de Chile

\section{Introduction}

Chile is located on the tectonic convergent contact between the Nazca and South American plates, where large tsunamigenic subduction earthquakes occur, like the $M_{w} 8.8$ Maule earthquake in 2010 (Madariaga et al. 2010; Lay et al. 2010; Vigny et al. 2011), and the largest event recorded is $M_{w} 9.5$ Valdivia earthquake in 1960 (Plafker and Savage 1970; Astiz and Kanamori 1986; Cifuentes 1989; Barrientos et al. 1992; Vita-Finzi and Mann 1994; Lomnitz 2004). Almost all the cities in the Chilean country have experienced a megaor large-thrust earthquake in the last century. In addition to that, seismic hazard is also associated with large inland intermediate-depth earthquakes like the $M_{s} 8.3$ Chillán earthquake in 1939 (Campos and Kausel 1990), less recorded shallow crustal events which have occurred mainly along the main Andes Cordillera $\left(M_{w} 6.3\right.$ Las Melosas earthquake in 1958, Alvarado et al. 2009; Sepulveda et al. 2008; Legrand et al. 2007; $M_{w} 6.3$ Aroma earthquake in 2001, Farías et al. 2010; $M_{w} 6.5$ Curicó earthquake in 2004) and large magnitude aftershocks like those following the 2010 Maule earthquake which occurred near Pichilemu in March 11th, 2010 (Farías et al. 2011; Ryder et al. 2012). Reliable assessment and mitigation of seismic hazards along active tectonic zones like the Chilean subduction margin are therefore challenging problems with clear economic and societal implications.

Understanding crustal seismicity in the Andes of Central Chile is a main issue regarding seismic hazard assessment of the city of Santiago. The recently reported San Ramón Fault, a Quaternary active kilometric-scale west-vergent thrust fault system located at the foot of the West Andean Thrust (Armijo et al. 2010), represents a conceptual change regarding the seismic hazard assessment in the region, until now almost exclusively focused on subduction mega-thrust earthquakes. Although previous studies focused on probabilistic seismic hazard assessment in the Metropolitan Region of Chile (Leyton et al. 2010), it is necessary to improve seismotectonics characterization related to the seismically active character of this fault, as well as its potential impact on the Santiago Metropolitan area given different deterministic seismic rupture scenarios. 
Deterministic seismic hazard assessment can be supported from the identification of geologically active structures, whose previous activity can or cannot be evidenced in the usually reduced historic instrumental record (Convertito et al. 2006; Cultrera et al. 2010; Raghu Kanth and Dash 2010). The San Ramón Fault has been recently identified like a geologically active fault which can produces large magnitude crustal earthquakes, in the range of $M_{w}$ 6.9-7.4 (Armijo et al. 2010). Precise location and determination of focal mechanisms of associated seismicity can be particularly useful to improve knowledge on potential seismic activity of this structure.

First-order predicting ground-motion parameters given different earthquake scenarios can be achieved through the development of empirical relationships that relate a specific characteristic of the ground motion with few parameters, such as magnitude and distance to the seismic source (e.g., Sabetta and Pugliese 1987; Ambraseys et al. 1996; Abrahamson and Silva 1997; Boore et al. 1997; Kanno et al. 2006). To obtain these empirical relationships is difficult in zones characterized by moderate seismicity rates and limited seismological records.

Like an alternative strategy, it is possible to compute synthetic broadband accelerograms from a deterministic approach using earthquake rupture source models combined with seismic wave propagation numerical schemes (e.g., Berge et al. 1998; Bernard et al. 1996; Mai and Beroza 2003; Ruiz et al. 2007). Recorded accelerograms are naturally complex because of the high-frequency content, which depends on site effects as well as on path and seismic source effects which can affect ground-motion variability too. As a result, near-fault stations can exhibit very different spectral and temporal seismic records.

Here, we performed a detailed analysis of seismic events reported by the SSN (National Seismological Service of the University of Chile) in order to establish their potential link with recent crustal-scale tectonic structures. Also, we present results from first-order ground-motion predictions for an $M_{w} 6.9$ earthquake rupturing the San Ramón Fault, using the methodology proposed by Ruiz et al. (2011), which is based on a kinematic fractal $k^{-2}$ earthquake rupture source model. We simulated broadband strong ground motion in the near-fault region for several different seismic rupture scenarios, to focus on source effects and kinematic rupture complexity. We statistically analyzed and compared ground-motion parameters predicted by empirical attenuation laws (Kanno et al. 2006), with the ones obtained numerically in this work for different earthquake rupture scenarios.

\section{The San Ramón Fault system}

Along Central Chile, the Nazca plate subducts beneath the South American plate at a rate of $6.8 \mathrm{~cm} /$ year (Demets et al. 1994; Vigny et al. 2009). The main Andes Cordillera in this region is mostly constituted by Mesozoic to Cenozoic volcanic and sedimentary rocks together with Cenozoic intrusives (Thiele 1980; Charrier et al. 2002, 2005; Farías et al. 2010; Armijo et al. 2010). The San Ramón Fault is an N-S fault system located at the eastern border of the city of Santiago at the foot of the mountain front associated with the continental-scale West Andean Thrust (Armijo et al. 2010), where the San Ramón hill range reaches 3,249 $\mathrm{m}$ a.s.l. At Cenozoic timescale, the San Ramón Fault is a part of a crustal-scale reverse west-vergent ramp fault system, which resulted in the abrupt relief change that separates the central depression of Santiago valley (mean altitude of 500-550 m a.s.1.), with respect to the main Andes Cordillera (Armijo et al. 2010; Rauld 2011). 
The structural system is constituted by fault segments in the order of 10-15 km length, and the associated transfer zones properly characterized between the Maipo and Mapocho rivers (Armijo et al. 2010; Rauld 2011), which most probably continues to the north and to the south of the known area (Fig. 1). According to crustal-scale structural model deduced from detailed geological mapping, the San Ramón Fault system rooths the crust dipping $36^{\circ}-62^{\circ} \mathrm{E}$ until $10-12 \mathrm{~km}$ depth, where a major overthrust dipping $4^{\circ}-5^{\circ} \mathrm{E}$ is located (Armijo et al. 2010; Rauld 2011). Conspicuous ca. 4-200 m height fault scarps systematically located along the fault trace disrupt the surface all along the piedmont at the eastern border of Santiago valley, providing evidence for Quaternary manifestations of fault activity. Together with the geometry and structure of the fault, this suggests slip rate in the order of $\sim 0.4 \mathrm{~mm} /$ year (Armijo et al. 2010). These results support the geologically active character of this fault system, along which large magnitude earthquakes in the range of $M_{w}$ 6.9-7.4 could be potentially expected (Armijo et al. 2010).

\section{Seismological survey results}

\subsection{Analysis of the seismicity}

Reliable database with hypocentral locations is paramount for a coherent study on crustal seismicity, to assess the potential seismic activity of faults.

\subsubsection{Crustal velocity model}

It is broadly known that typical problems associated with the hypocentral location of local and regional earthquakes are the imprecision in the calculated arrival times of seismic waves, an inadequate velocity model and the consequent instabilities of inverse methods. Because the epicentral distances are usually greater than the distances between seismic stations, the hypocentral parameters cannot be precisely determined, resulting in a strong dependency between the timing and focal depth of seismic events, which complicates the later interpretation regarding how the spatial distribution of the seismicity is structured.

In this study, we first analyzed velocity models previously proposed for the study zone (Barrientos et al. 2004; Pardo 2012 personal communication), to generate a new and improved crustal velocity model for the studied region that allows for a better determination of the focal parameters of the cordilleran crustal seismicity.

A database with 669 events was chosen and used to invert a 1D velocity structure model. Seismic crustal events were selected to build up a database based on the following criteria: hypocentral depth ranging from 0 to $30 \mathrm{~km}$, epicenter located between $32.5^{\circ}-$ $34.5^{\circ} \mathrm{S}$ and $69.5^{\circ}-71.5^{\circ} \mathrm{W}$, events recorded by a minimum of $12 \mathrm{SSN}$-network seismic stations, date of occurrence between 2000 and 2011 and a minimum of approximately 20 readings of $\mathrm{P}$ - and $\mathrm{S}$-wave phases, with residual less than $0.5 \mathrm{~s}$.

To invert a 1D velocity model, we used the technique developed by Kissling et al. (1995) and implemented on the Velest program. This code simultaneously allows for the relocalization of hypocenters and the adjustment of a 1D velocity model by an iterative process and by means of the inversion of seismic wave arrival times, using a nonlinear ray tracing methodology. The final velocity model is a stack of homogeneous layers defined by seismic wave velocities and travel-time station corrections. To solve the problem, the theory of seismic ray trajectory (ray tracing) from the source to the receiver is applied to calculate the direct ray, the refracted one and optionally the reflected ray that result from 


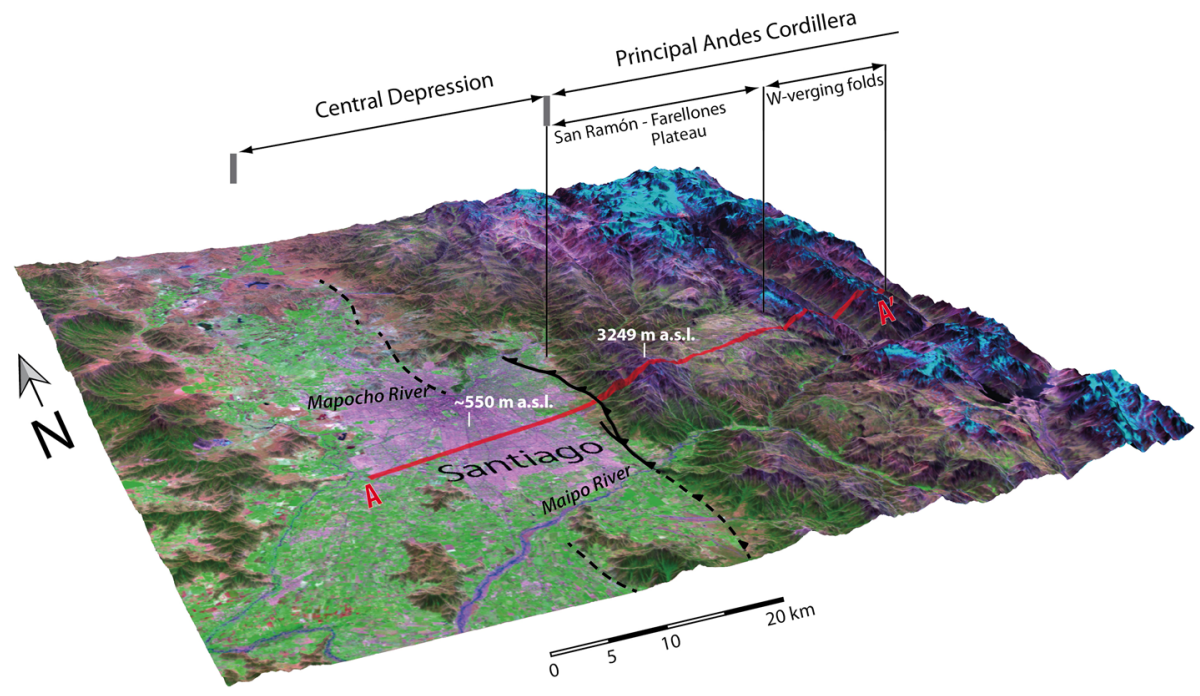

Fig. 1 South-west bird's eye view of the Santiago Metropolitan area highlighting the San Ramón Fault and the major geological features of the Principal Andes Cordillera, according to Armijo et al. (2010). Black solid line represents the mapped fault trace, and black dashed line is the inferred fault trace. The red line A$A^{\prime}$ delimits the length of the vertical cross-section shown latter

the velocity model. The inverse problem is thus solved using a damped least-square algorithm, because the seismic wave travel-time inversion is nonlinear, the solution is obtained by an iterative scheme.

The crustal velocity model obtained is shown in Fig. 2. It basically consists of three layers, where the seismic waves are faster in the first layer compared to the velocity model used by the SSN. The Moho discontinuity is located around $47 \mathrm{~km}$ depth and the $V_{p}$-to- $V_{s}$ ratio found is 1.75 .

\subsubsection{Seismotectonic analysis}

We selected 2,770 crustal seismic events (depth $<30 \mathrm{~km}$ ) from the SSN database, which were relocated using the 1D velocity model obtained in this study. Figure 3 shows the spatial distribution of the seismicity for the studied zone. Besides a heterogeneous pattern distribution, one can observe a quite delimited clustered seismicity. In particular, several seismic events were located nearby or directly beneath some seismological stations which are located in the cordilleran zone. Among these receivers, one can list broadband stations, such as San José de Maipo (SJCH), Las Melosas (LMEL), El Yeso (YECH) and Farellones (FAR).

The crustal seismicity is spatially organized in approximate $\mathrm{N}-\mathrm{S}$ direction, along two parallel strips (Fig. 3). Type A strip is located between $70.6^{\circ}$ and $70.8^{\circ} \mathrm{W}$ and has events similar to each other in terms of waveforms, S-P travel times and their focal mechanisms, as will be shown later. A second type B strip is located from $70.4^{\circ}$ to $70.0^{\circ} \mathrm{W}$ and has instead events with a great diversity in terms of waveforms, high scatter in S-P travel times and their focal mechanisms. Furthermore, we find that the $\mathrm{N}-\mathrm{S}$ band of seismicity near the Santiago basin, or type A, is well defined with a width $<15 \mathrm{~km}$ along the E-W direction, focal depths around $\sim 10-15 \mathrm{~km}$ with little dispersion and epicenters having a distribution 
Fig. 2 Comparison of the final crustal $1 \mathrm{D}$ velocity model $\left(V_{p}\right)$ obtained in this study (black wider line) and the one used by the SSN for the same study region (black thin line)

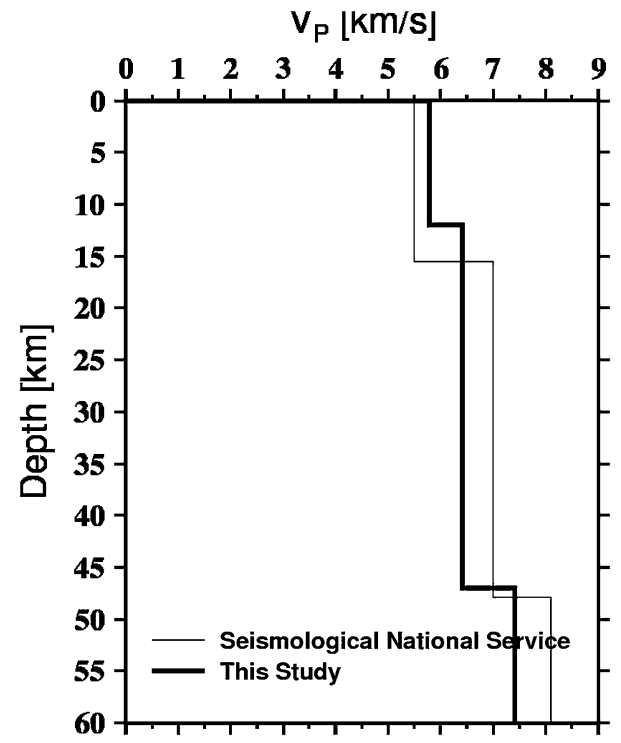

approximately parallel to the fault trace of the San Ramón Fault; the type B band, also of predominantly $\mathrm{N}-\mathrm{S}$ direction and located within the Principal Cordillera, has a greater dispersion along the E-W direction and a range of variation of focal depths between 0 and $10 \mathrm{~km}$, with a higher concentration of events in the southern end $\left(34^{\circ} \mathrm{S}\right)$. This study confirms independently, conclusions pointed out by Barrientos et al. (2004) and Charrier et al. (2005), that most of the seismic activity is located near the Chile-Argentina boundary, which is aligned with the El Fierro Fault system. Between the type A and B strips $\left(70.45^{\circ}\right.$ and $70.55^{\circ} \mathrm{W}$ ), one can observe a sparse seismicity as shown in Fig. 3.

As mentioned before, several seismic events are located nearby and directly beneath some seismological stations installed in the cordilleran zone. In order to validate-or calibrate and verify-the hypocentral location (latitude, longitude and depth) of this shallow crustal seismicity, a detailed waveform analysis was performed by doing both, particle motion as well as an analysis of S-P travel times for each one of the events located under the stations.

The waveforms analysis, by calculating P-wave particle motion, confirms the quality of the hypocentral relocation results obtained with VELEST. This is because both are verified, epicentral coordinates and depth of these events, which allow us to verify the quality of the 1D velocity crustal model. Specifically, the P-wave particle motion analysis allowed the accurate calculation of the angles of incidence, $i$, at the station, allowing then to check that the hypocenters are located just below the station. The angle of incidence obtained varies around values, $i<5^{\circ}$. It further shows that the seismicity near Santiago, under SJCH and FAR stations, is characterized by similar waveforms and S-P travel times of around $1.2 \mathrm{~s}$.

An example of observed ground velocity waveforms (Z, E-W and N-S components) for events located under $\mathrm{SJCH}$ station is shown in Fig. 4a. Notice that the $\mathrm{P}$ waveforms ( $Z$ component) have the same signature, with only minor differences in their amplitudes. The E-W component also confirms that these events have similar signatures and waveforms between the P-wave and the S-wave window; in addition, the comparison of seismic wave arrival times also shows that the S-P travel times have little fluctuation among 


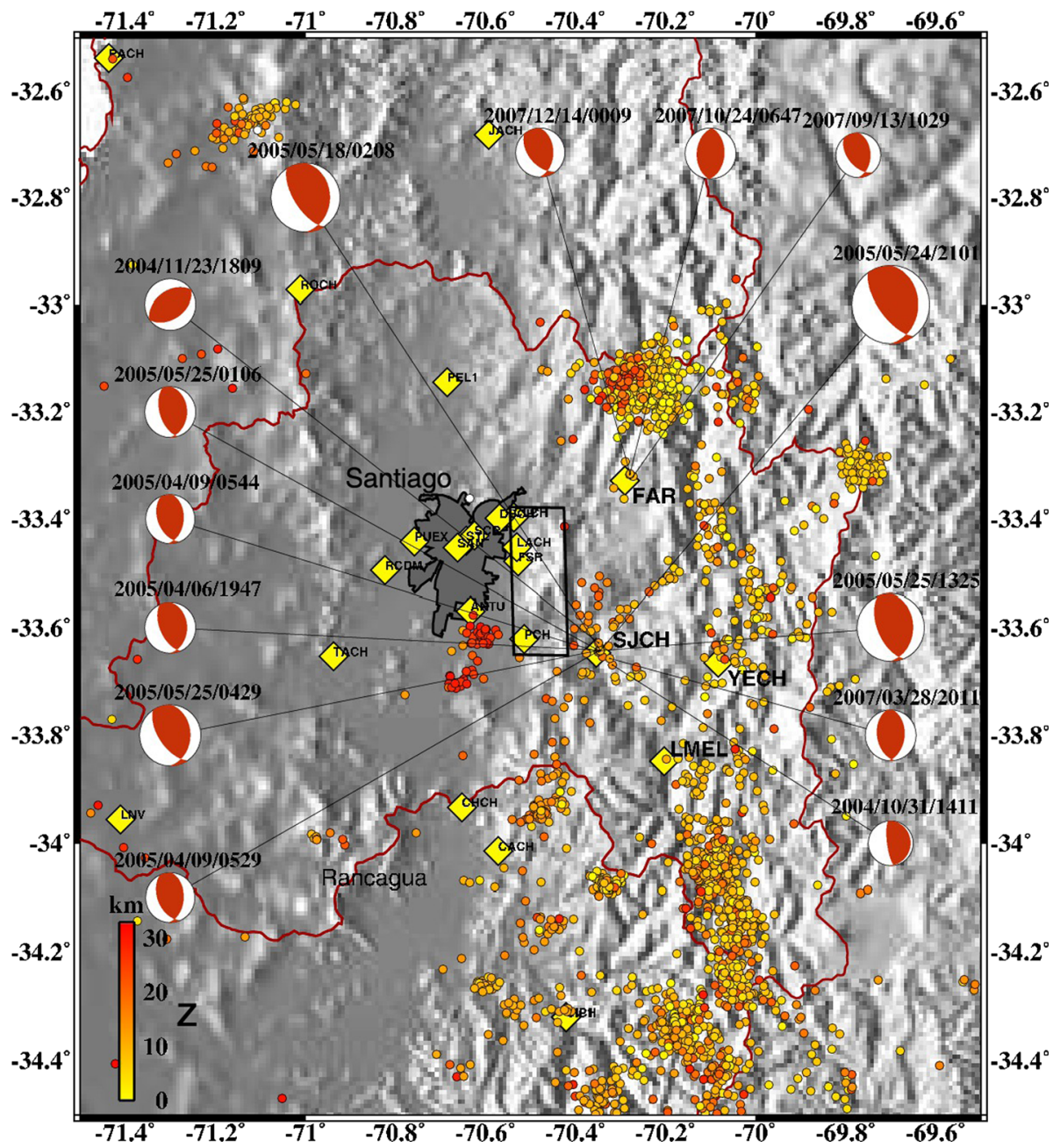

Fig. 3 Map showing the final hypocenter location of the 2,770 cortical events (small circles) recorded by the SSN between 2000 and 2011. Events were relocated using the improved 1D velocity model; color scale bar shows the focal depths. Focal mechanism solutions are displayed for clustered events located under $\mathrm{SJCH}$ and FAR stations. Solid black line rectangle represents the limits of the San Ramón Fault plane projected to the surface. Yellow diamonds are seismological stations from the SSN. The closed dark gray polygon represents the city of Santiago

events. The comparison of $\mathrm{N}-\mathrm{S}$ component recording confirms that these events generated practically the same waveform at the station for the three components. The seismic activity mentioned above is concentrated around $9-13 \mathrm{~km}$ depth ( 8 of 13 events are located around $9 \mathrm{~km}$ depth) for the cluster under SJCH and focal depth around $9 \mathrm{~km}$ for the cluster under FAR station.

Two clusters of seismicity are located underneath LMEL and YECH broadband stations. These events generated different waveforms and they are characterized by more scattered S-P travel times, which is quite consistent with their focal depth fluctuations between 6 and $13 \mathrm{~km}$. An example of velocity waveforms (three components, Z, E-W, N- 

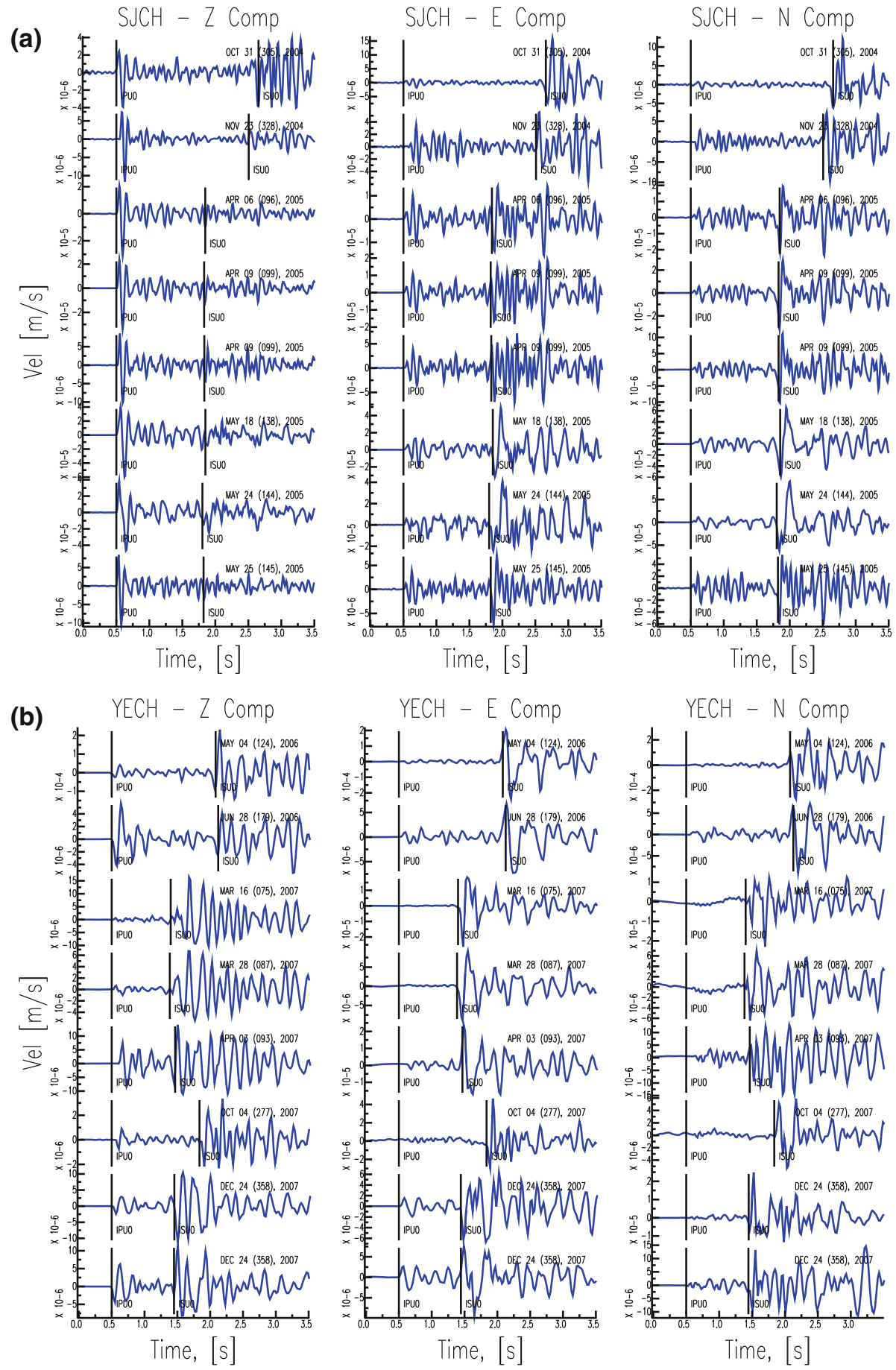

Fig. 4 Example of observed velocity waveforms (three components) for events clustered under a SJCH and b YECH stations. Vertical solid line marks the P- and S-wave arrival times 
S) for events located underneath YECH station is displayed in Fig. 4b. Despite the great diversity in their waveforms and S-P travel times, one can notice that few records have the same waveform, which can be observed from the three components of velocity recordings.

According to this new observational evidence and taking into account that the waveforms of seismic events under SJCH and FAR stations are similar to each other (i.e., they all have the same waveform signature, which are the "so-called" multiplets in the literature), one can conclude and confirm tectonic seismic activity in the fault zone at a depth of about $10 \mathrm{~km}$. This result is consistent with the detachment zone inferred from the structural model proposed for the San Ramón Fault (Armijo et al. 2010), resulting that the observed seismicity at the detachment level can be associated with a single source of brittle deformation.

Forward modeling was done to compute the complete displacement seismic wave field in a layered medium for a buried point source and a given focal mechanism, using the AXITRA code (Coutant 1990) implemented following Bouchon's (1981) method. Calculations of synthetic seismograms allowed us to perform simultaneous adjustments of synthetic and observed waveforms for the three components, by matching the polarity and amplitude of the P- and S-waves (East and North component). Different focal mechanisms and magnitudes were tested by comparing manually the waveforms fitting. Because the recorded events are small in magnitude and station coverage is scarce, the waveform modeling adjustment was simply done at a single station. As initial guessed solution, and considering the results described previously, it was assumed a focal mechanism consistent with the geometry of the fault plane at the detachment level proposed by Armijo et al. (2010). Then, a systematic exploration of focal mechanism parameter was done by tuning strike, dip and rake angles, but keeping these values within a broad range consistent with the fault plane geometry assumed from the proposed detachment level (Armijo et al. 2010).

Figure 5 shows an example of velocity waveforms fitting for a seismic event located under and registered at SJCH station, occurred in 2005. Synthetic seismograms are compared to the observed ones bandpass filtered between 0.5 and $5 \mathrm{~Hz}$ for this analysis.

On the lights of the results obtained from waveform modeling, one can conclude that the seismic events associated with SJCH and FAR stations are located at an average depth of 9-10 km, essentially having the same focal mechanism, characterized by an N-S reverse fault with a dip between $30^{\circ}$ and $40^{\circ}$, a rake of about $100^{\circ}-120^{\circ}$ and an S-P travel time of $1.2 \mathrm{~s}$ with little dispersion (Fig. 6). Figure 3 resumes the whole set of focal mechanisms obtained in the study region. Additionally, earthquakes located under LMEL and YECH stations present greater dispersion of epicenters and focal depths that we relate with diffuse deformation zones, which agrees rather well with more complex seismicity pattern along the Principal Andes Cordillera. Also, these events are characterized by large variability on their waveforms and diversity of focal mechanisms that we associate with the brittle deformation zone proposed for this area.

Considering the tectonic model proposed by Armijo et al. (2010), it is possible to explain not only the distribution of seismicity observed at depth, but also to connect coherently the different types of focal mechanisms retrieved for the events studied - under the frame of this tectonic model-in order to explain the detachment zone at a proposed level of about $10 \mathrm{~km}$ depth for the San Ramón Fault.

Contrarily, it is difficult to associate the observed local shallow seismicity under the optic of an east vergent-dominant lithospheric scale fault responsible for the structure of the west Andes Cordillera (Farías et al. 2010). Therefore, to set earthquake rupture scenarios, we preferred the continental-scale West Andean Thrust (Armijo et al. 2010), in which the San Ramón fault participates playing a major role in building the mountain front 


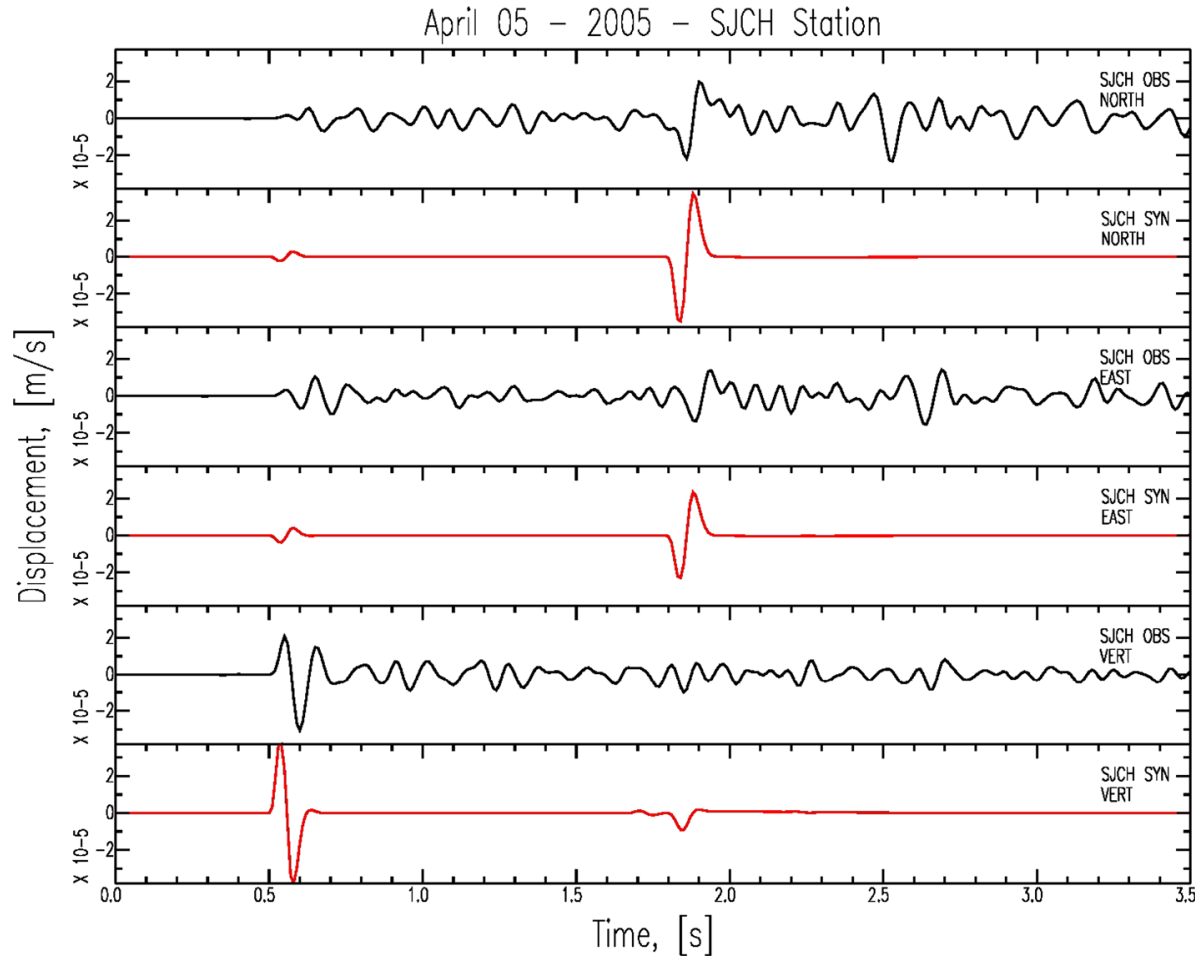

Fig. 5 Example of the velocity waveform fit (three components), for a single seismic event located under SJCH station

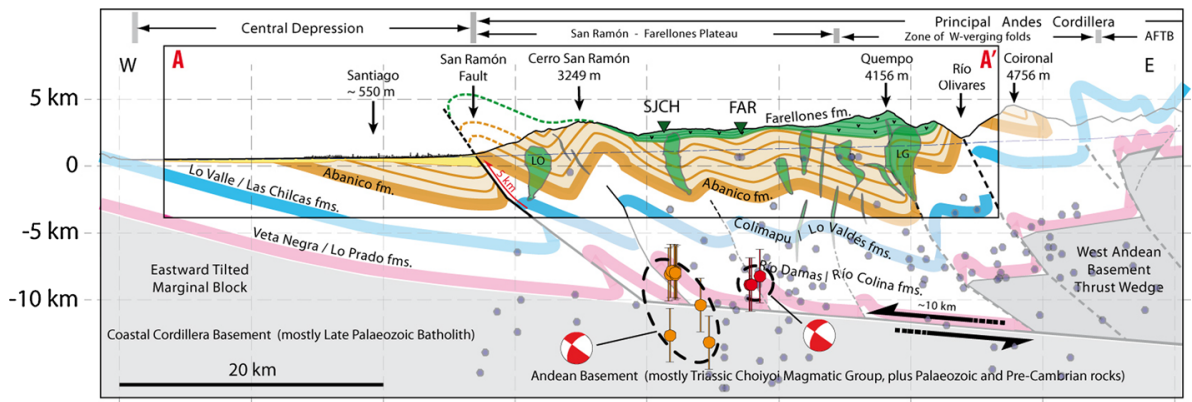

Fig. 6 Vertical cross-section made along the $A-A^{\prime}$ profile shown in Fig. 1. It shows the major geological features along the western Principal Andes Cordillera and the detachment ramp zone that connects with the San Ramón Fault toward the surface at the eastern border of the city of Santiago (Armijo et al. 2010). Orange circles represent the events located under SJCH and red circles correspond to events clustered under FAR. The beach balls plotted highlight the dominant focal mechanism for the set of events studied

at the western border of the main Andes Cordillera of Central Chile, like a tectonic framework consistent with the seismological observations shown and discussed in this work.

As a first conclusion, we propose that the San Ramón Fault is not only a geologically active fault, but also it presents seismicity that can be associated with this structure at 
depth, resulting in a seismically active fault too. This is a primary element to be considered in any study on seismic hazard assessment for the entire Metropolitan area and in particular for the city of Santiago.

\section{Kinematic earthquake rupture scenarios for an $M_{w} 6.9$ in the San Ramón Fault}

This section focuses on the study of the variability of ground-motion parameters computed numerically by simulating several kinematic earthquake rupture scenarios in the San Ramón Fault. The estimate of ground-motion parameters allows to measure and interpret the amplitude, duration and characteristic periods of seismic ground motion at some specific locations. We simulated broadband strong ground motion in the near-fault region for several different seismic rupture scenarios for an $M_{w} 6.9$ in the San Ramón Fault, which is the minimum from the largest magnitude range (6.9-7.4) estimated for potential large earthquake ruptures from previous geological studies (Armijo et al. 2010; Rauld 2011). The modeling focuses on source effects radiated by a complex stochastic kinematic fractal $k^{-2}$ composite seismic source. The proposed scenarios are defined by changing some critical source parameters, such as rise-time, rupture velocity, rupture initiation point and heterogeneous slip distribution, to better understand their influence on the simulated ground motions in the vicinity of the San Ramón Fault.

The earthquake magnitude $M_{w} 6.9$ chosen in this study-to compute earthquake rupture scenarios-is consistent with the proposed magnitude range, belonging to a conservative margin, within the middle-upper range, which has served as a criterion to establish this magnitude. It is important to point out that the simulated earthquake rupture in this study does not break the free surface; if it did, we could expect magnitudes greater than 6.9, which may reaches the proposed maximum magnitude $M_{w} 7.4$ from geological studies; so, making a potential earthquake scenario on the San Ramón Fault rupturing along the total known length and width, as well as breaking the free surface. Thus, we decided to model a more conservative earthquake at this level, and to increase rupture complexities in further studies that would permit us to simulate the maximum possible event for the San Ramón fault.

\subsection{Strong ground-motion simulation methodology: kinematic fractal $k^{-2}$ source model}

It is well known that the complexity of the rupture process of the seismic source is the main responsible of dominating the ground motions in the near-fault region. The spatial variability of seismic ground motions is given by the fact that it is controlled by the combination of three effects, the so-called, source, path and local site effects. In this study, the target region is located nearby and right over the fault zone, allowing us to concentrate on source effects, before to include site effects (e.g., Pilz et al. 2011).

At close distances comparable with few fault lengths, the finite-source effects such as rupture directivity effects, hanging-wall/foot-wall effects, low-frequency pulses, radiationpattern effects, etc., as well as, slip heterogeneities and spatial variations on rupture velocity, strongly control the complexity of wave radiation from the seismic source and the intensity of ground motions. Among these finite-source effects, the rupture directivity, which changes according to the angle between the receiver and rupture propagation direction, strongly controls the ground motions. It is observed when the rupture front propagates toward the site, increasing the amplitudes of the ground motion, shortening the 
apparent source duration and concentrating the seismic energy in a short time window. The rupture directivity effect has been analyzed since the earliest kinematic models proposed by Haskell (1964) and Ben-Menahem (1961), the latter author introduced the rupture directivity coefficient, $C_{\mathrm{d}}$. Directivity effect has been observed from strong-motion recordings in the $1992 M_{w} 7.3$ Landers, California earthquake (e.g., Cotton and Campillo 1995; Wald and Heaton 1994; Aochi and Fukuyama 2002), in the $1999 M_{w}$ 7.6 Chi-Chi, Taiwan, earthquake (e.g., Oglesby and Day 2001) and in the $1994 M_{w} 6.7$, Northridge earthquake (e.g., Wald et al. 1996).

In order to model broadband strong ground motion in the near-fault region, we follow the approach proposed by Ruiz et al. (2011). It is based on a composite source description where subevents are generated using a fractal distribution of sizes and, by summation, produce spatially heterogeneous $k^{-2}$ slip distributions. Subevents are distributed uniformly random over the whole fault plane. Each elementary source is described as a crack-type slip model growing circularly from a nucleation point, which is triggered when the macroscale rupture front (starting from the hypocenter) reaches it. In the rupture process, a scaledependent nucleation region is introduced at the subevent scale, in order to control the rupture directivity effect at high frequencies. It is done through the setting of $R_{c}$ and $h$ parameters, that both control the extension of the nucleation region in which is located the nucleation point. It does that for smaller sources the nucleation point is randomly chosen within the crack, so, disorganizing the rupture directivity at small scales. For instance, if $h=0$, the nucleation region collapses to a point and the rupture at the subevent scale propagates in average following the same direction as the macro-scale rupture front. Instead, for $h=1$, the nucleation region covers the whole area of the subevents (with sizes $R<R_{c}$ ), therefore, the small-scale rupture direction is totally disorganized.

For simplicity, a constant rupture velocity is assumed at large and small scales. Each subevent is set up with a scale-dependent rise-time, assuming a boxcar source-time function, hence filtering out its own high-frequency radiation. The resulting slip-velocity function from adding up all the subevents that contributes to a fault-point has a shape similar to the ones obtained from dynamic earthquake rupture model. In addition, the total kinematic rupture process behaves as a propagating slip pulse because of the scaledependent rise-time defined on the model. Synthetic ground motions are computed by convolving the resulting slip-velocity function at each point on the fault with the respective numerical Green's function.

It has been shown that, in the far-field approximation, the acceleration spectrum follows the $\omega^{2}$ model with amplitudes controlled by a frequency-dependent directivity effect. As discussed in Ruiz et al. (2011), by introducing a size-dependent nucleation region at all scales $(h>0)$, it will reduce directivity effects. We expect that this will be also the case for the rupture scenarios analyzed in this work. We decided to keep $h=0$, to simplify the statistical analysis and to focus on other finite-source effects and source parameters, as shown later.

\subsection{Fault setting and source model parameters}

The location and rupturing fault dimensions were defined according to the crustal-scale structural model and potential large earthquakes from the fault (Armijo et al. 2010). Synthetic ground motions were computed for an $M_{w} 6.9$ earthquake on the inverse San Ramón Fault, setup with a focal mechanism equal to $358^{\circ} / 40^{\circ} / 113^{\circ}$ (strike/dip/rake). A single rectangular fault plane of dimensions, $L \times W=30 \times 16 \mathrm{~km}^{2}$, was defined and the fault top was buried at $1.0 \mathrm{~km}$ depth. 
The 1D velocity model obtained in this study was used, but slightly modified in the kinematic rupture scenarios to propagate seismic waves. Because we focus mainly on source effects radiated by a complex kinematic rupture model, in this work, we neglected site amplifications due to local site/soil or basin/topographic effects, for instance. However, in the ground-motion simulations, a low-velocity layer was inserted at the top of the 1D velocity model retrieved with VELEST. The thickness and $V_{s}$ were set as $500 \mathrm{~m}$ and $1,040 \mathrm{~m} / \mathrm{s}$, respectively. The thin top layer attempts to capture in a simple way the low velocity wave propagation of the sedimentary basin at the City of Santiago. A direct evaluation of an approximate formula relating $V_{s}$ and depth (Pilz et al. 2011) gives $V_{s} \sim 1,177 \mathrm{~m} / \mathrm{s}$ estimated at $250 \mathrm{~m}$ depth, then this value is in the order of the one used in our simulations.

The complete seismic wave field of Green's functions was computed up to $10 \mathrm{~Hz}$ using the AXITRA code (Coutant 1990), which is based on the discrete wave number (DWN) method (Bouchon and Aki 1977; Bouchon 1981). Green's functions are unfiltered and numerically valid up to $10 \mathrm{~Hz}$, under the validity hypothesis of the DWN method and the assumption of a constant $Q$-factor to model intrinsic attenuation (Kjartansson 1979). The receivers are evenly distributed at the surface (with a grid spacing of about $4 \mathrm{~km}$ ), covering over and around the fault, spreading out over the whole Santiago Metropolitan area (Fig. 7). The fault plane was discretized on an uniform grid spacing defined by $N_{x}=512$, and $N_{y}=128$, subfaults along strike and along dip, respectively.

Several different kinematic rupture scenarios were defined by varying physical rupture source parameters, such as the hypocenter location on the fault, rupture velocity $\left(V_{r}\right)$, final slip distribution and rise-time $\left(R_{p}\right)$. Five random heterogeneous fractal $k^{-2}$ slip distributions are used (Fig. 8a-e) and were generated assuming a constant stress drop for all subevents $\left(\Delta \sigma_{\mathrm{d}}=9 \mathrm{MPa}\right)$. Slip is computed following the fractal composite $k^{-2}$ source model scheme (Ruiz et al. 2011). We consider five hypocenter locations (Fig. 8f), which are intended to span purely unilateral, bilateral and up-dip ruptures. The $V_{r}$-to- $V_{s}$ ratio is set up to $0.7,0.8$ and 0.9 , while the maximum rise-time, $\tau_{\max }$, defined through the $R_{p}$ parameter, $\tau_{\max }=a R_{p} / V_{r}$, is set up according to $R_{p}=0.1 \mathrm{~W}$ and $0.2 \mathrm{~W}$, the $R_{c}$ parameter is kept so that $R_{c}=R_{p}$. Let us recall here that the rise-time is scale-dependent, where $a=2$ and $R_{p}$ define the radius beyond which the rise-time is constant $\left(\tau_{\max }\right)$. For all these parameter combinations, we simulate strong ground motion to estimate synthetic groundmotion parameters, such as PGA and PGV.

\subsection{Kinematic rupture scenario analysis}

In the following subsections, we present the results obtained from numerical simulation and the analysis focuses on the variability of ground-motion parameters. The simulated parameters are also compared against empirical ground-motion prediction equations by Kanno et al. (2006). These equations calibrated for PGA, PGV and response spectra were obtained using strong-motion recordings from K-NET and KIK-NET databases, including recordings of earthquakes from the USA and Turkey in order to enlarge the database for shallower events (depth $<30 \mathrm{~km}$ ). This attenuation law is chosen because it provides several empirical curves (PGA, PGV and response spectra) using only a minimum set of parameters, such as AVS30 (shear-wave velocity averaged over the first $30 \mathrm{~m}$ of depth), magnitude and source distance. For all next sections, the empirical curves were computed using $\operatorname{AVS} 30=1,040 \mathrm{~m} / \mathrm{s}$, after the $V_{s}$ value of the inserted thin layer at the top.

In this study, the observational constraint we used is that no synthetic source model based on a realistic distribution of rupture scenarios and source-station geometries should 


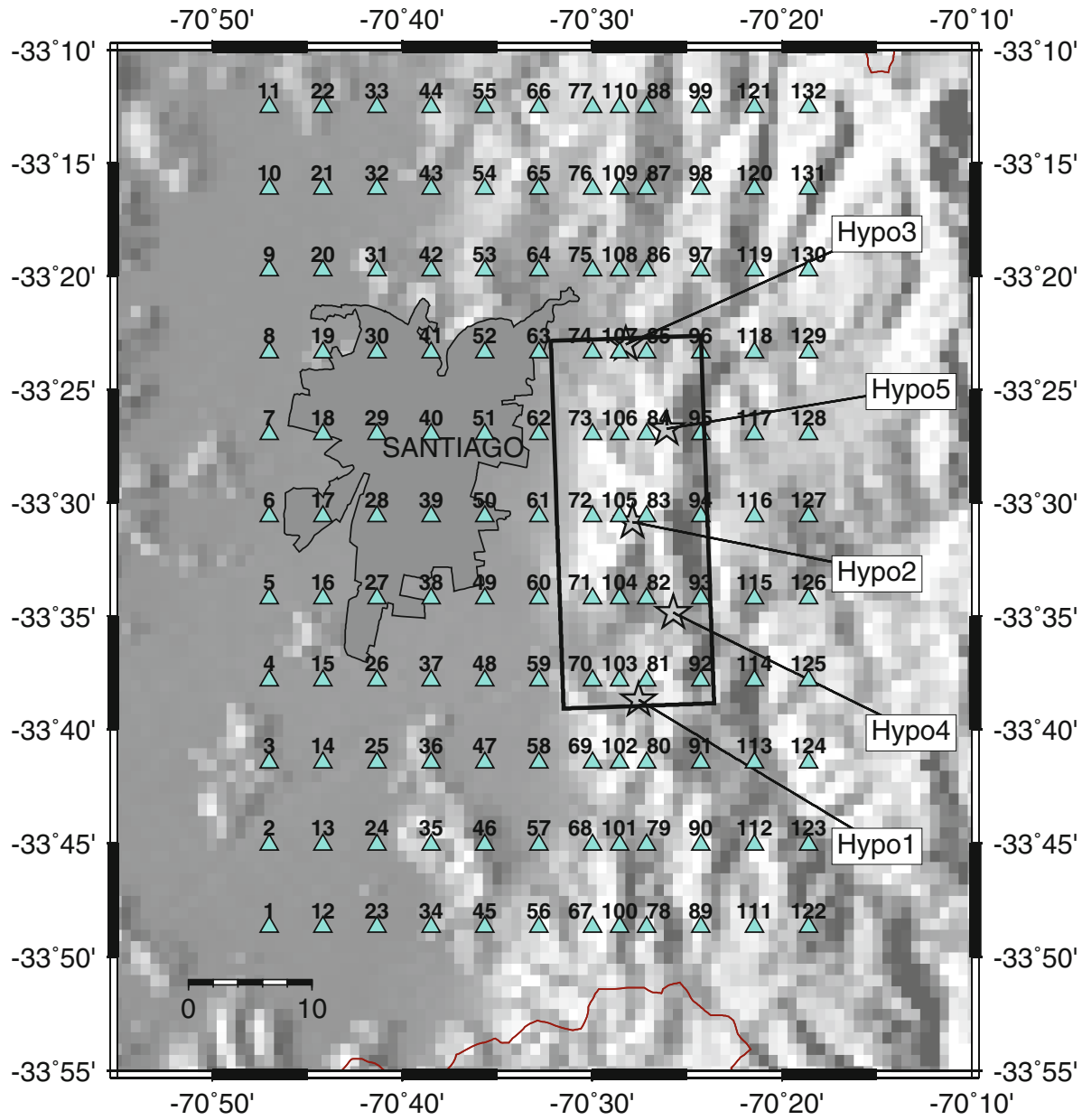

Fig. 7 Map of the Santiago Metropolitan area and the spatial distribution of the receivers (light cyan triangles) used in the simulation for an $M_{w} 6.9$ earthquake in the San Ramón Fault. The solid black line (rectangle) represents the fault plane projection onto the free surface of the simulated fault. Gray light stars correspond to the epicenter location of the five hypocenters defined in the rupture scenarios simulations

generate standard deviation (SD) on strong-motion parameters larger than the empirical ones.

\subsubsection{Effect of variability of the hypocenter location}

Figure 9 shows the effect on ground-motion parameters, the horizontal PGV (PGVH), when changing the hypocenter location. These values were estimated for each hypocenter using the entire set of source parameters defined in the rupture scenario simulations, i.e., $V_{r}$-to- $V_{s}$ ratio equal to $0.7,0.8$ and 0.9 , and $R_{p}$ fixed to equal $0.1 \mathrm{~W}$ and $0.2 \mathrm{~W}$.

The synthetic PGVH mean values (Fig. 9a) as well as its SDs associated with each hypocenter (Fig. 9b) are shown as a function of the source distance. The mean and SD were estimated for each hypocenter by bin of source distance. Both numerical results are 
(a)

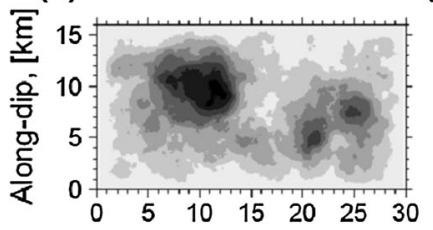

(d)

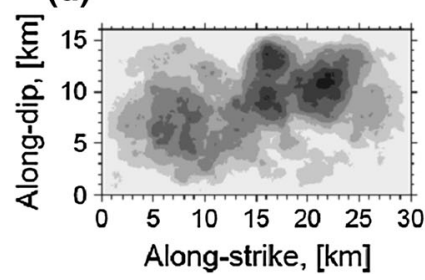

(b)

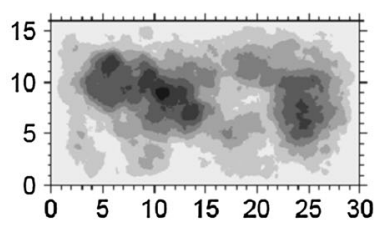

(e)

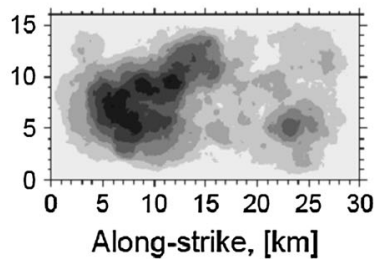

(c)

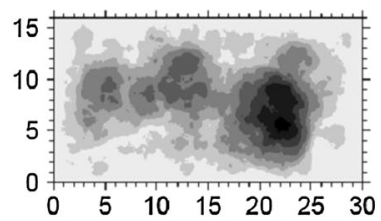

(f)

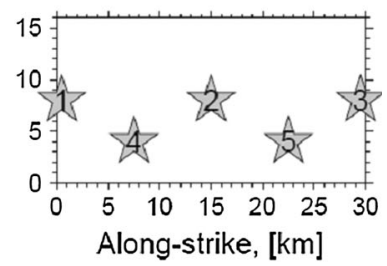

Fig. 8 a-e Five random fractal composite $k^{-2}$ slip distributions used to build up the rupture scenarios. f Five hypocenter locations (gray stars) defined in the simulations
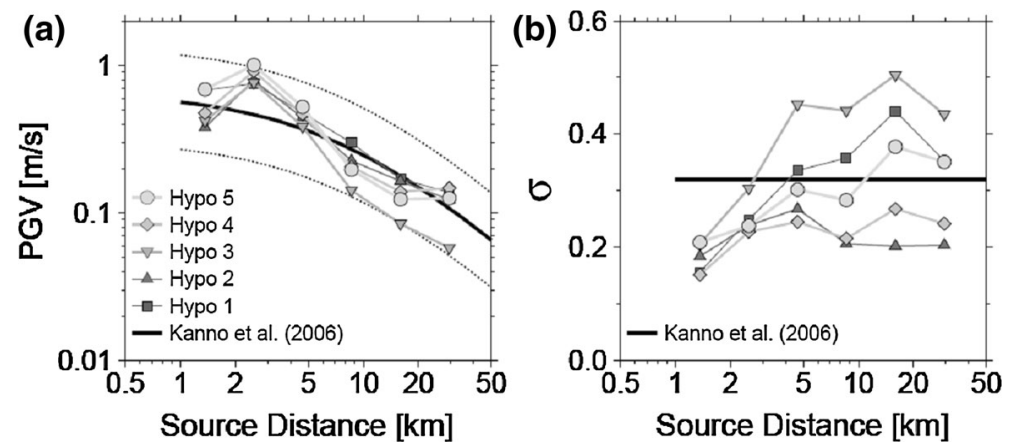

Fig. 9 Comparison of simulated mean horizontal PGV obtained for each hypocenter location and the empirical attenuation relationship proposed by Kanno et al. (2006). a Mean PGVH values and b SD, where solid black lines represent the empirical mean curve ( $\pm \mathrm{SD}$, dashed lines) and the empirical SD value, respectively. Results are plotted as a function to the source distance

compared against the PGV empirical mean curve $( \pm S D)$ and the empirical SD value proposed by Kanno et al. (2006).

In general, there is a good agreement between synthetic and empirical values, in both cases, for the whole range of distances considered. Hypocenter 3, which corresponds to an $\mathrm{N}-\mathrm{S}$ rupture along the San Ramón Fault (a purely forward rupture directivity) the numerical mean values underestimate the empirical mean ones, but stay within the margin of desired dispersion. For all hypocenter locations, one can observe at a distance of around $2 \mathrm{~km}$, a significant increase in the mean PGVH value with respect to the empirical mean curve that could be related to a directivity effect.

Figure $9 \mathrm{~b}$ shows the numerical PGVH SD variability with source distance. It is observed that at short distances $(R<5 \mathrm{~km})$ all synthetic values keep below the empirical level, in general, having a small amount of scatter. This, however, does not hold true for hypocenter 3 , that displays larger values for $R>3 \mathrm{~km}$. On the other hand, at larger 

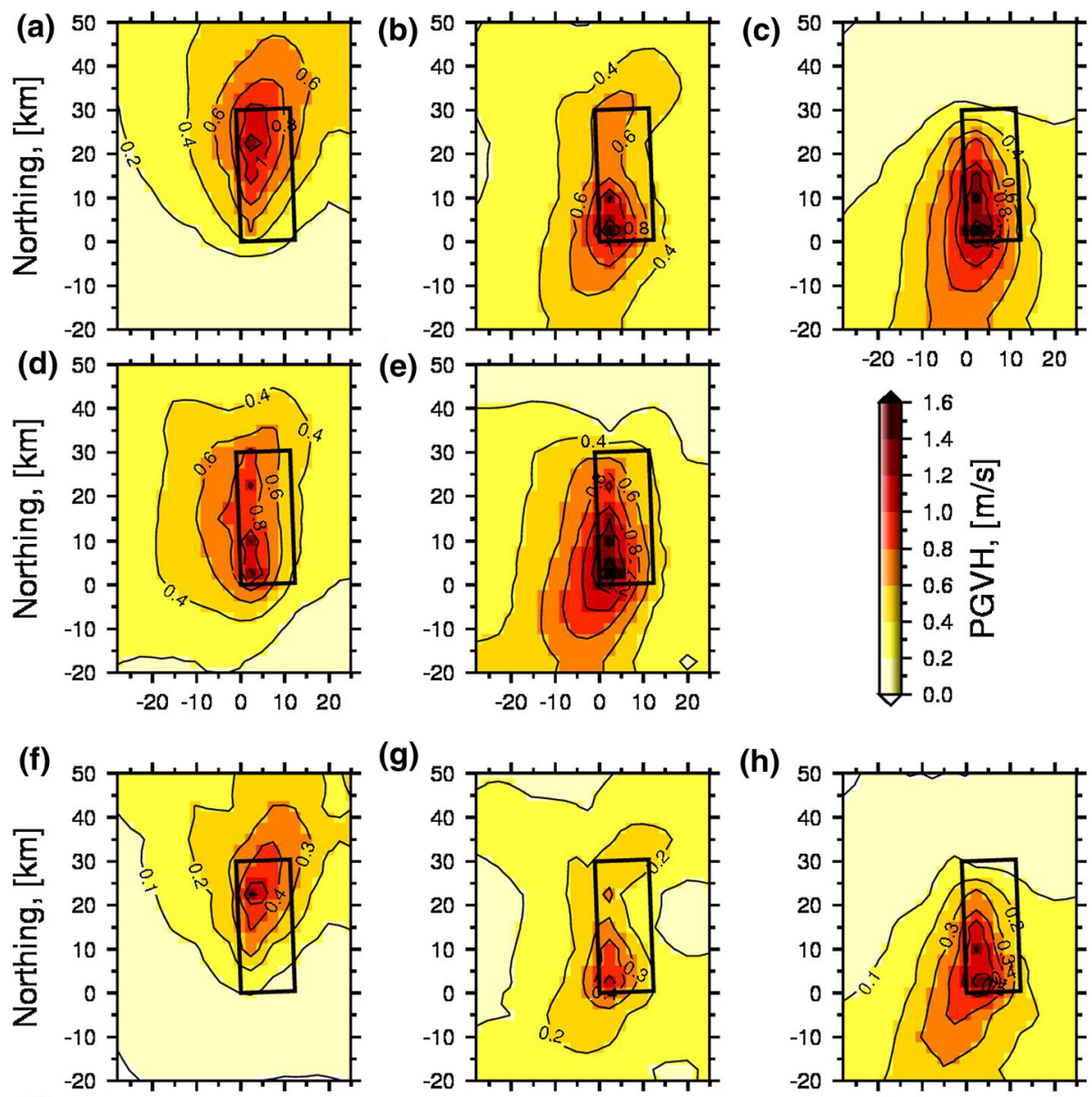

(g)
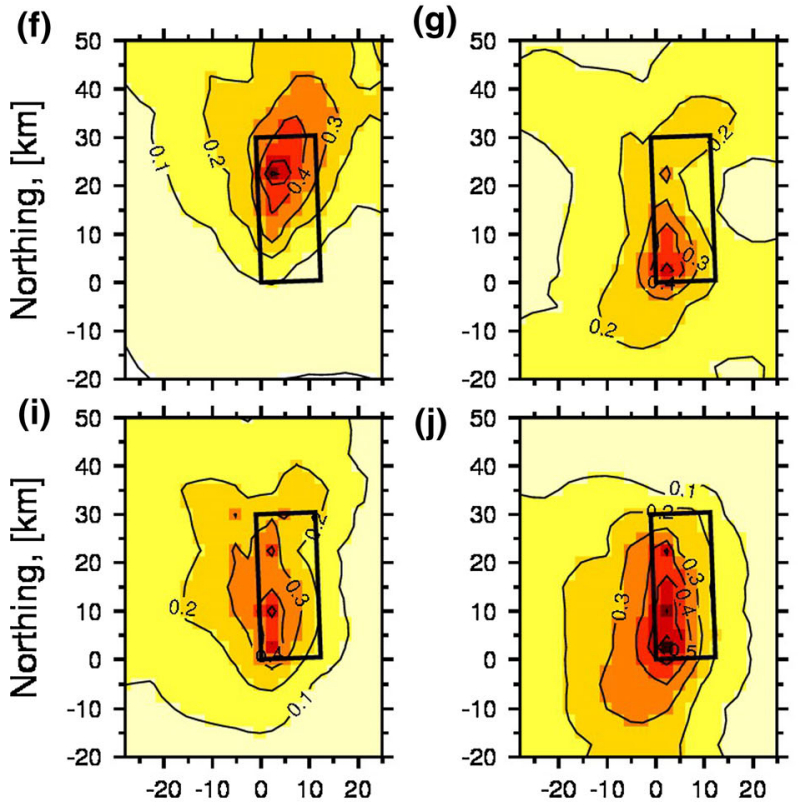

(h)

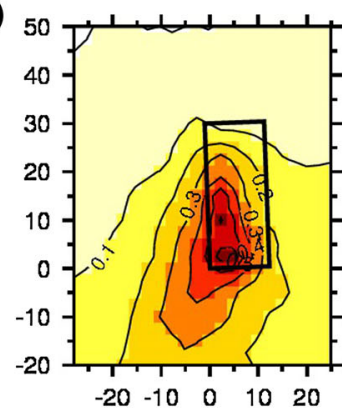

Easting, [km]

Easting, [km]

Fig. 10 Isocontour maps for PGVH computed for each hypocenter location. Mean PGVH for a hypocenter 1 , b hypocenter 2 , c hypocenter 3 , d, hypocenter 4 and e hypocenter 5 . Their corresponding SD estimates are for $\mathbf{f}$ hypocenter $1, \mathbf{g}$ hypocenter $2, \mathbf{h}$ hypocenter $3, \mathbf{i}$, hypocenter 4 and $\mathbf{j}$ hypocenter 5 . The black solid line rectangle corresponds to the San Ramón Fault projected to the surface 

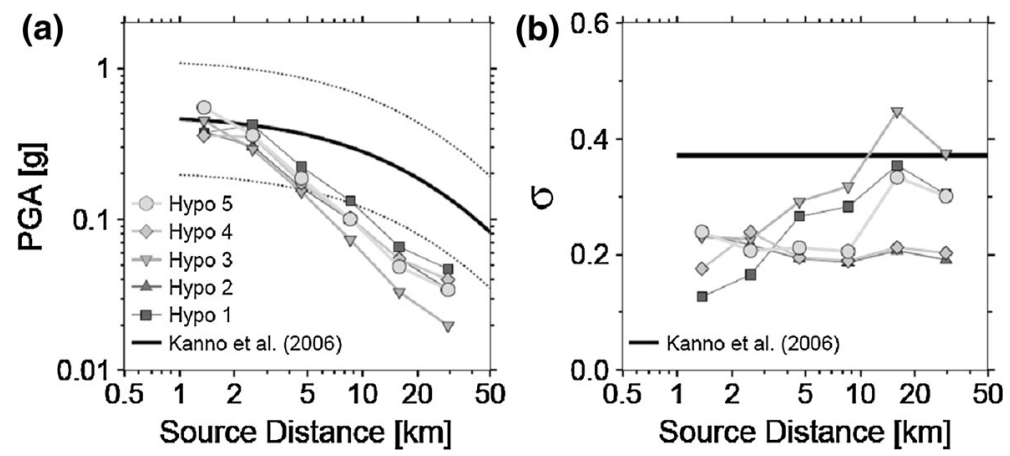

Fig. 11 Comparison of simulated mean horizontal PGA estimated for each hypocenter location and the empirical attenuation relationship proposed by Kanno et al. (2006). a Mean PGVH values and b SD estimates, where solid black lines represent the empirical mean curve ( $\pm \mathrm{SD}$, dashed lines) and the empirical SD value, respectively. Results are plotted as a function to the source distance

distances from the source $(R>5 \mathrm{~km})$, simulations related to unilateral rupture propagation, such as hypocenter 1 ( $\mathrm{S}-\mathrm{N}$ rupture) and hypocenter $3(\mathrm{~N}-\mathrm{S}$ rupture), present an increasing in their SD values. On the contrary, hypocenter 2 (bilateral rupture), hypocenter 4 (up-dip S-N rupture) and hypocenter 5 (N-S up-dip rupture) have SD which are less or comparable to the empirical ones.

Figure 10 presents isocontour maps for the simulated mean PGVH (Fig. 10a-e) and their corresponding SD (Fig. 10f-j) associated with each of the five hypocenter locations. The spatial distribution highlights clearly a strong effect of the rupture directivity toward the south, by increasing the amplitudes in the case of an $\mathrm{N}-\mathrm{S}$ and $\mathrm{N}-\mathrm{S}$ up-dip ruptures propagation (Fig. 10c, e). Similar effect is observed toward the north in a case of an $\mathrm{S}-\mathrm{N}$ and S-N up-dip ruptures (Fig. 10a, d). The purely bilateral rupture (Fig. 10b) does not exhibit any particular strong effect associated with the directivity; one can observe a more symmetrical and uniform isocontours.

There is observed a common pattern in all the hypocenter location results, except in the one corresponding to a unilateral $\mathrm{S}-\mathrm{N}$ rupture (hypocenter 1, Fig. 10a), and it is observed near the SW area of fault plane projected onto the surface and corresponds to the maximum mean PGVH modeled reaching values of about $1.4 \mathrm{~m} / \mathrm{s}$ (Fig. 10b-e). This amplification effect could be related to the slip direction onto the fault plane, notice that the slip vector has a small dextral component along strike.

This systematic observation coincides with the fact that the largest PGVH values are localized in the hanging wall of the San Ramón Fault (Fig. 10b-e). Based on empirical observations, recent studies have proposed that peak ground motions from thrust earthquakes can be 20-30 \% larger than from strike-slip earthquakes. It has also been shown that the hanging wall systematically exhibits amplified near-field ground motion in comparison to the footwall (e.g., the 1971 San Fernando earthquake, the 1980 El Asnam, Algeria earthquake and the 1994 Northridge earthquake; Chang et al. 2004).

The SD isocontour maps (Fig. 10f-j) show the same spatial behavior discussed previously (i.e., the effects of the rupture directivity and the maximum deviation values located in the SW area over the fault). The largest SD of about 0.6 is observed in Fig. 10h, that corresponds to an $\mathrm{N}-\mathrm{S}$ unilateral rupture that coincides with the prior discussion, where unilateral ruptures introduce largest uncertainties on ground-motion parameters. 
Figure 11 shows the variability on the horizontal PGA (PGAH) when changing the hypocenter location. The synthetic mean PGAH value (Fig. 11a) as well as their SD estimates associated with each hypocenter (Fig. 11b) is shown as a function of the source distance. These values were estimated for each hypocenter using the complete set of parameters defined in the scenarios, i.e., $V_{r}$-to- $V_{s}$ ratio equal to $0.7,0.8$ and 0.9 , and $R_{p}$ equal to $0.1 \mathrm{~W}$ and $0.2 \mathrm{~W}$. The results are compared against the PGA empirical mean curve ( \pm SD) proposed by Kanno et al. (2006).

The simulated mean PGAHs are, in general, in good agreement with the empirical values at close distances from the source, $R<4 \mathrm{~km}$, for all hypocenter locations. Simulated mean values gradually decrease with distance, where the average synthetic values fall below the empirical mean curve minus SD for distances greater than $10 \mathrm{~km}$; at larger distances, the numerical predictions attenuate, on average, faster than the empirical ones. This can be attributed to the fact that the high-frequency content of synthetic Green's functions computed in this study simplifies seismic wave propagation in a real medium. Path effects, such as, scattering, high-frequency seismic wave attenuation, for instance, strongly control the high-frequency content radiated from the source and then affect PGA values.

Figure $11 \mathrm{~b}$ shows a comparison between the PGAH SD estimated as a function of the source distance for all five hypocenters. The simulated SD values are systematically lower than the empirical deviation for the whole range of distances. However, this does not hold true for hypocenter 3 (N-S rupture), because at a distance of about $20 \mathrm{~km}$ the simulated SD overestimates the empirical deviation. Overall, the results are coherent with the observational constraint we assumed that says that none synthetic source model based on a realistic distribution of rupture scenarios, fault geometry and receiver distribution should not generate SD of ground-motion parameters larger than the empirical ones.

Figure 12 presents isocontour maps for the simulated mean PGAH values (Fig. 12a-e) and their SDs (Fig. 12f-j) associated with each hypocenter location. The effect of rupture directivity is significantly lower than in the previous case $(\mathrm{PGVH})$, exhibiting a more symmetrical-like spatial pattern, so the directivity effect is controlled at high frequencies as one can see in these simulations. Let us recall that this has been shown in the fractal $k^{-2}$ composite source model (Ruiz et al. 2011), pointing out that the rupture process breaks the directivity at small scales, that is to say, at the scale of subevents. A common pattern in all hypocentral location, except the one corresponding to a unilateral S-N rupture (hypocenter 1, Fig. 12a), is observed in the vicinity near the SW corner of the San Ramón Fault plane projected onto the surface, and it corresponds to the maximum mean PGAH value modeled reaching a peak of about $0.7 \mathrm{~g}$. Similar to PGVH case, maximum simulated mean values of PGAH are located in the hanging wall of the Ramón Fault (Fig. 12a-e), but also large mean values are observed off the fault plane projected to the surface, thereby covering areas near the fault trace.

The SD isocontour maps (Fig. 12f-j) show a more heterogeneous spatial distribution, and the maximum simulated SDs estimated for each hypocenter location do not always coincide with the area located near the SW corner of fault plane projected onto the surface. The maximum SD is observed in Fig. $12 \mathrm{j}$, corresponding to the $3 / 4$ bilateral rupture reaching a peak value of about $0.3 \mathrm{~g}$.

\subsubsection{Effect of the rupture velocity}

Figure 13 shows the effect on ground-motion parameters (PGVH) when varying the rupture velocity $\left(V_{r} / V_{s}=0.7,0.8\right.$ and 0.9$)$. The synthetic mean PGVH values as well as their SDs, associated with each $V_{r}$-to- $V_{s}$ ratio, are shown as a function of the source distance. 

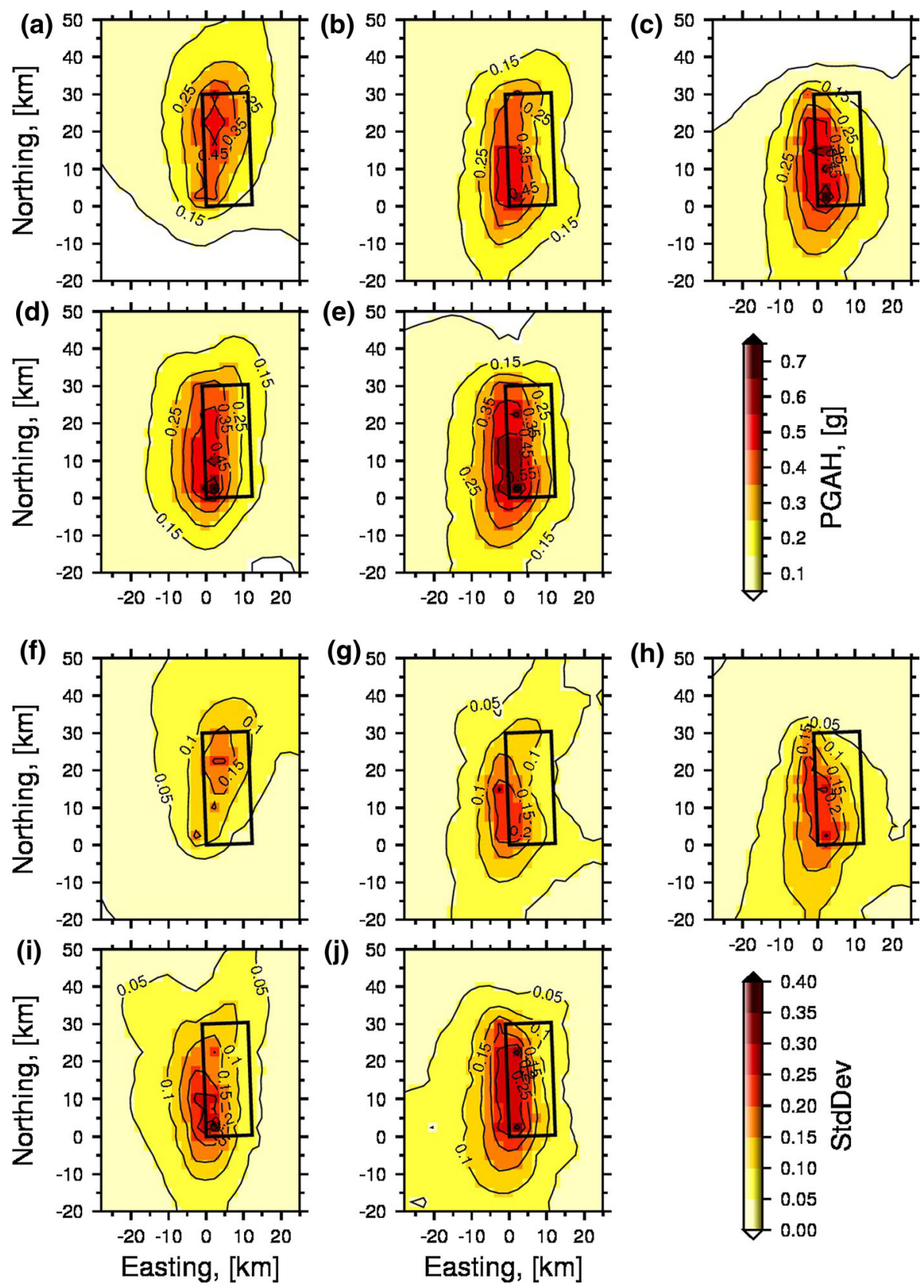

Fig. 12 Isocontour maps for PGAH computed for each hypocenter location. Mean PGAH for a hypocenter 1 , b hypocenter 2, c hypocenter 3, d, hypocenter 4 and e hypocenter 5 . Their corresponding SDs are for f hypocenter $1, \mathbf{g}$ hypocenter $2, \mathbf{h}$ hypocenter 3 , $\mathbf{i}$, hypocenter 4 and $\mathbf{j}$ hypocenter 5 . The black solid line rectangle corresponds to the San Ramón Fault projected to the surface 

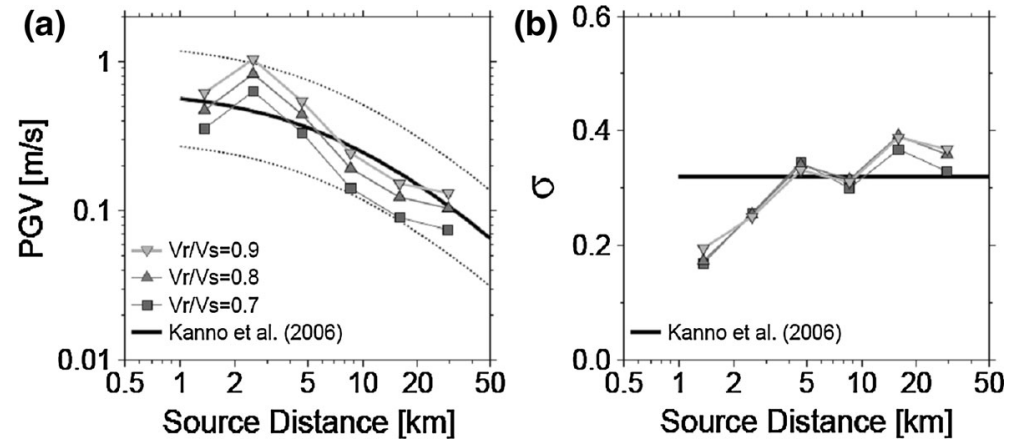

Fig. 13 Comparison of simulated mean horizontal PGV estimated for each $V_{r}$-to- $V_{s}$ ratio and the empirical attenuation relationship proposed by Kanno et al. (2006). a Mean PGVH values and b SD, where solid black lines represent the empirical mean curve ( $\pm \mathrm{SD}$, dashed black lines) and the empirical $\mathrm{SD}$ value, respectively. Results are plotted as a function to the source distance

In this statistical analysis, a subset of source parameters explored in the simulation is chosen, that is to say, selecting hypocenter 2,4 and 5 , and $R_{p}=0.1 \mathrm{~W}$ and $0.2 \mathrm{~W}$. In this case, purely unilateral ruptures are not included in the statistics, it is assumed (i.e., hypocenter 1 and 3) that they are not such usual rupture behavior, and from a statistical point of view they may bias the analysis; on the other hand, predominantly unilateral-like ruptures are taken into account (hypocenter 4 and 5).

Figure 13a shows the simulated mean PGVH values estimated by bin of source distance for each $V_{r}$-to- $V_{s}$ ratio and compared against the empirical curves proposed by Kanno et al. (2006). The results show a good agreement between the modeled and empirical values. When increasing the $V_{r}$-to- $V_{s}$ ratio, the simulated mean values increase for all distances. At a distance of 2-3 km, there is also observed a significant increase in the mean PGVH for all $V_{r}$-to- $V_{s}$ ratios that could be related to the directivity effect.

Figure 13b shows the comparison between the simulated PGVH SD estimated for each $V_{r}$-to- $V_{s}$ ratio, as a function of the source distance. The modeled SD falls below the empirical value for all source distances up to $10-15 \mathrm{~km}$, and beyond this distance, there is a slight increase in the synthetic value. Notice that the simulated SD values do not depend on the $V_{r}$-to- $V_{s}$ ratio.

Figure 14 displays the isocontour maps of the simulated mean PGVH (Fig. 14a, c, e) and their corresponding SDs (Fig. $14 \mathrm{~b}, \mathrm{~d}$, f) associated with each $V_{r}$-to- $V_{s}$ ratio explored. A common pattern is observed near the SW corner of the fault plane projected onto the surface (Fig. 14a, c, e) and corresponds to the maximum modeled PGVH values that increases slightly when increasing the rupture velocity. That is to say, with a higher $V_{r}$-to$V_{s}$ ratio, a higher mean $\mathrm{PGVH}$ is obtained, in this case the maximum peak reached is about $1.6 \mathrm{~m} / \mathrm{s}$ for $V_{r} / V_{s}=0.9$. A relatively homogeneous symmetrical spatial distribution is observed, exhibiting isocontours elongated approximately along the $\mathrm{N}-\mathrm{S}$ direction and where the directivity effect is smoothed out.

The SD isocontour maps (Fig. 14b, d, f) show maximum synthetic deviation values near the SW corner of the fault plane projected onto the surface in all the three $V_{r}$-to- $V_{s}$ ratios. The maximum SD value is about 0.8 (Fig. 14f) for a rupture velocity of $V_{r}=0.9 V_{s}$. Isocontour lines are elongated along strike, and asymmetrical lobes are observed at the 

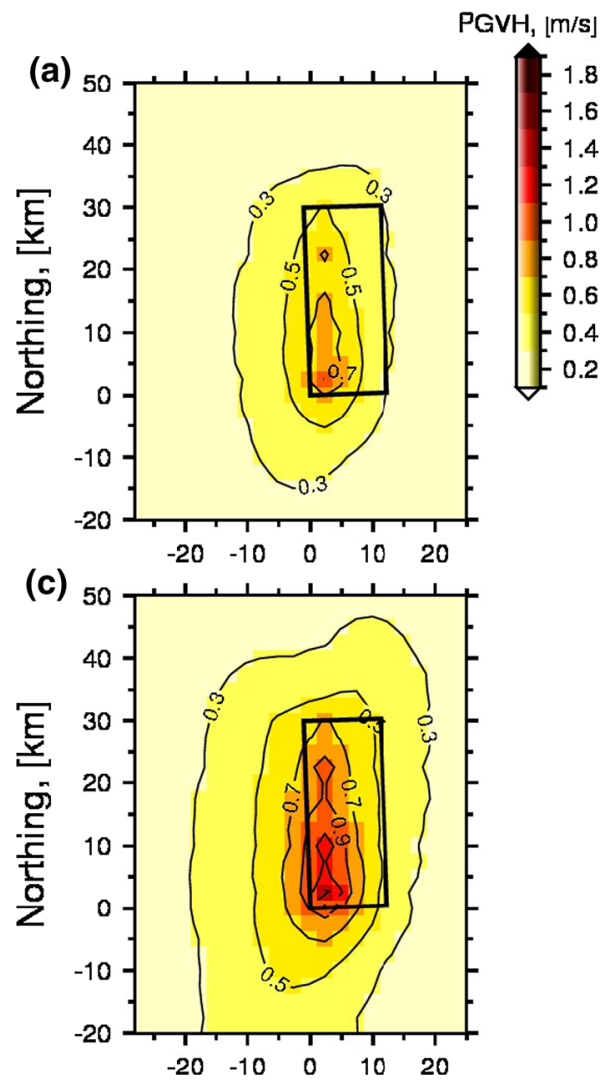

(d)

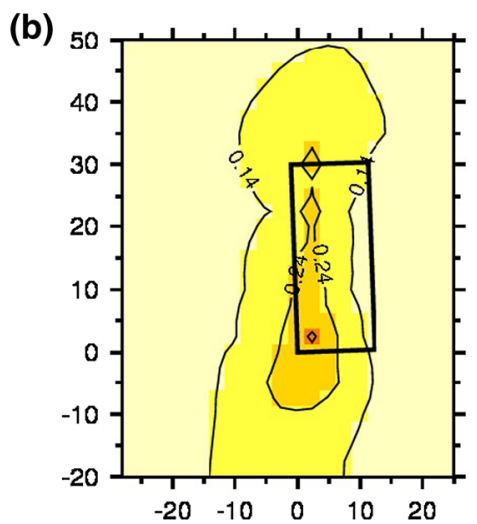

\section{StdDev}
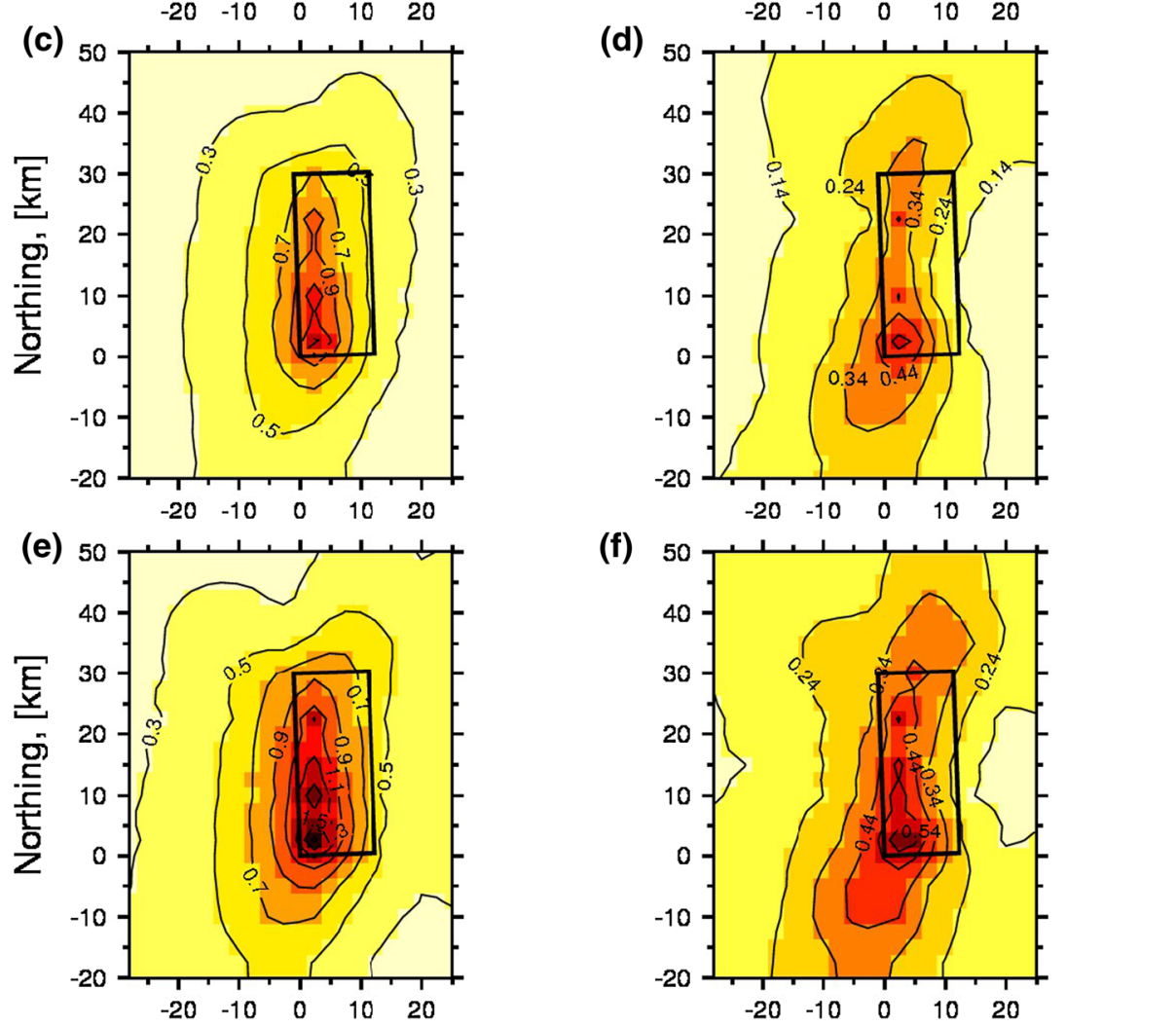

Easting, [km]

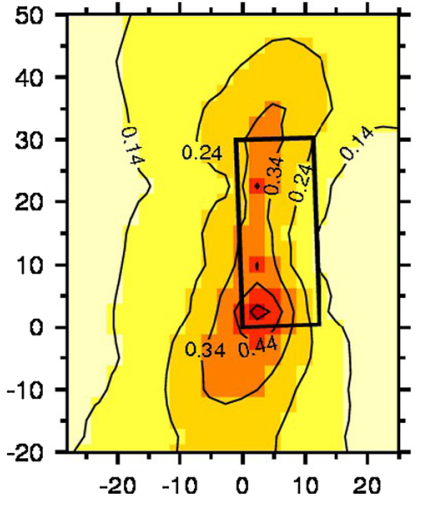

(f)

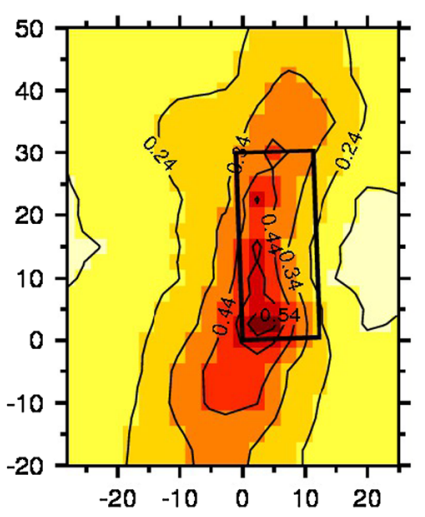

Easting, [km]

Fig. 14 Isocontour maps for PGVH computed for each $V_{r}$-to- $V_{s}$ ratio. Mean PGVH for a $V_{r} / V_{s}=0.7$, c $V_{r} /$ $V_{s}=0.8$, and $\mathbf{e} V_{r} / V_{s}=0.9$. Their corresponding SD is for $\mathbf{b} V_{r} / V_{s}=0.7, \mathbf{d} V_{r} / V_{s}=0.8$, and $\mathbf{f} V_{r} / V_{s}=0.9$. The black solid line rectangle corresponds to the San Ramón Fault projected to the surface

north and south ends of the fault. Notice that this map representation shows this asymmetrical distribution on the mean PGVH, which is hidden when estimating simulated SD by bin of source distance. 

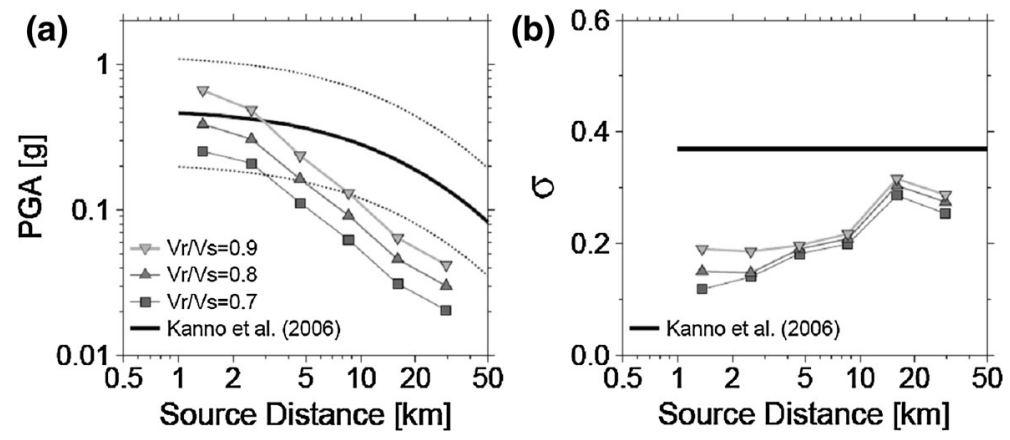

Fig. 15 Comparison of simulated mean horizontal PGA estimated for each $V_{r}$-to- $V_{s}$ ratio and the empirical attenuation relationship proposed by Kanno et al. (2006). a Mean PGAH values and b SD, where solid black lines represent the empirical mean curve $( \pm \mathrm{SD}$, dashed black lines) and the empirical $\mathrm{SD}$ value, respectively. Results are plotted as a function to the source distance

Figure 15 shows the effect on simulated PGAH when varying the $V_{r}$-to- $V_{s}$ ratio. The synthetic mean PGAH values (Fig. 15a) as well as their SDs estimated (Fig. 15b) for each rupture velocity are shown as a function of the source distance, and compared with the empirical attenuation law proposed by Kanno et al. (2006).

The synthetic mean PGAH (Fig. 15a) attenuates with distance faster that the empirical mean curve at short distances from the source the simulated mean values stay within the empirical mean $( \pm \mathrm{SD})$ range. At distances greater than about $4 \mathrm{~km}$, the simulated mean values become smaller than the empirical range, it can be mainly attributed to the effect of wave propagation at high frequencies more than deficiencies of high-frequency radiation emitted from the source. When increasing the $V_{r}$-to- $V_{s}$ ratio, there is an increasing in the mean PGAH values. On the other hand, Fig. 15b shows that the simulated SD falls below the empirical value for the whole range of distances and for the three $V_{r}$-to- $V_{s}$ ratios. At each bin of distance, there is observed a little scatter of synthetic SD estimates among different $V_{r}$-to- $V_{s}$ ratio values.

Figure 16 presents isocontour maps for the simulated mean PGAH (Fig. 16a, c, e) and their SD estimates (Fig. 16b, d, f) associated with each $V_{r}$-to- $V_{s}$ ratio. The maximum mean PGAH values are located in the SW area over the fault plane projected to the surface; however, large values are also distributed off the fault plane projection area (Fig. 16a, c, e). The synthetic mean PGAH increases when increasing the rupture velocity; the largest simulated maximum mean value is about $0.8 \mathrm{~g}$. A relatively symmetrical spatial distribution is observed, where PGAH isocontour lines elongate along the $\mathrm{N}-\mathrm{S}$ direction, so there is none strong directivity effect. In the case of the SD isocontour maps (Fig. 16b, d, f), the maximum deviations are located near the SW area over the fault. A maximum SD of about 0.3 is observed (Fig. 16f) for a rupture velocity equal to $0.9 V_{s}$. Isocontour lines are elongated $\mathrm{N}-\mathrm{S}$, and lobes appear at the north and south ends of the fault.

\subsubsection{Effect of the maximum rise-time, $\tau_{\max }$}

Figure 17 shows the effect on ground-motion parameters (PGVH) when varying the maximum rise-time, $\tau_{\max }$. In this analysis, notice that following the $\tau_{\max }$ definition, it is more sensitive to $R_{p}$ than $V_{r}$-to- $V_{s}$ ratio variations. Therefore, in this section, the statistical analysis focuses on $\tau_{\max }$ through $R_{p}$ values, defined as being equal to $0.1 \mathrm{~W}$ and $0.2 \mathrm{~W}$. 

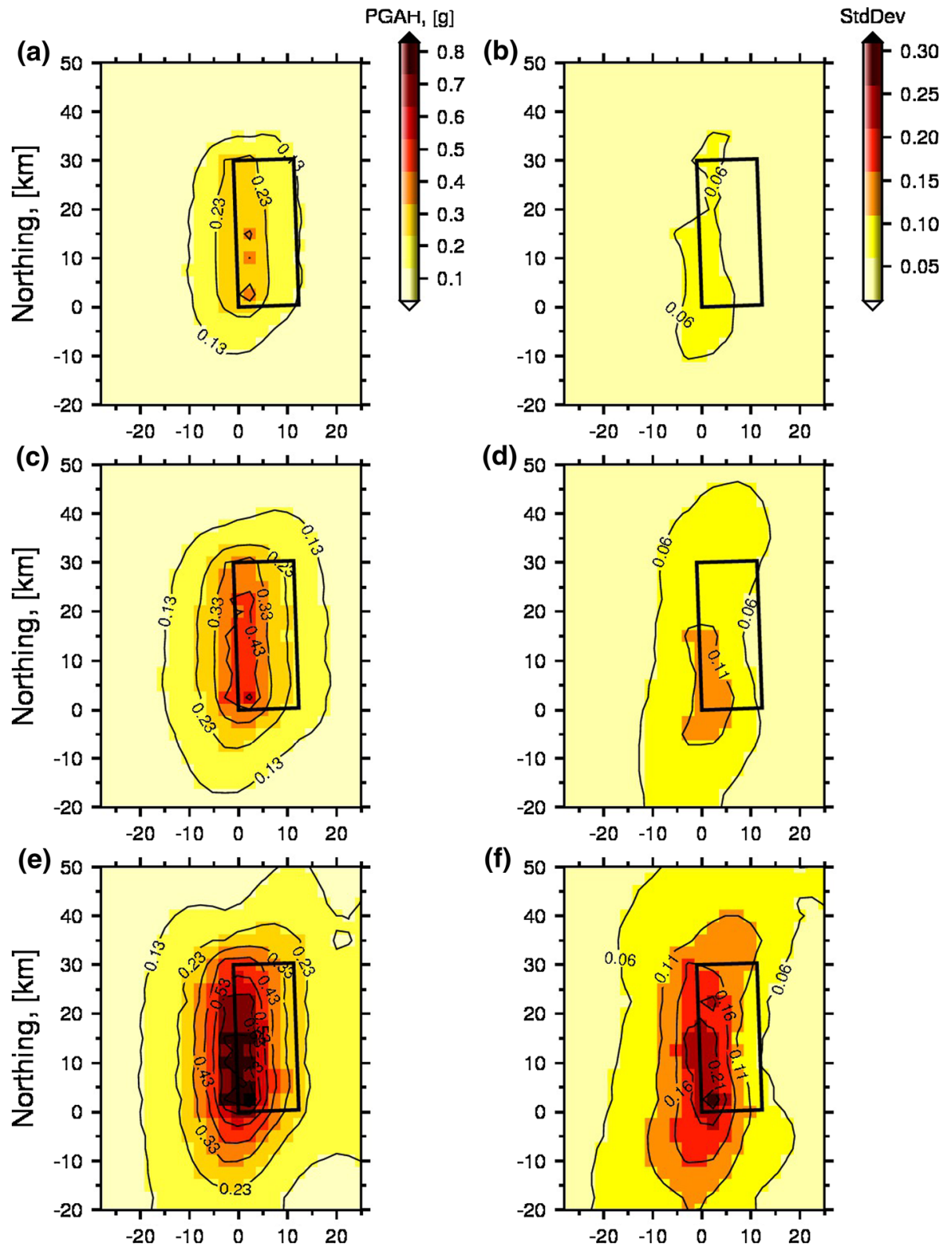

Easting, [km]

(f)

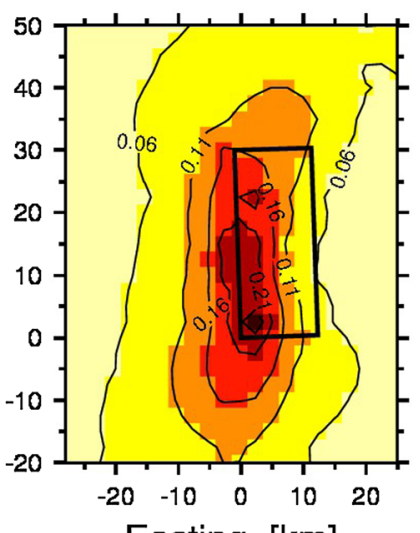

Fig. 16 Isocontour maps for PGAH computed for each $V_{r}$-to- $V_{s}$ ratio. Mean PGVH for a $V_{r} / V_{s}=0.7$, c $V_{r} /$ $V_{s}=0.8$, and e $V_{r} / V_{s}=0.9$. Their corresponding SD estimates are for $\mathbf{b} V_{r} / V_{s}=0.7$, d $V_{r} / V_{s}=0.8$, and f $V_{r} / V_{s}=0.9$. The black solid linerectangle corresponds to the San Ramón Fault projected to the surface

The synthetic mean PGVH values (Fig. 17a) as well as their SDs (Fig. 17b) are shown as a function of the source distance, and compared against empirical attenuation laws (Kanno et al. 2006). These values were estimated for each $R_{p}$ value by choosing a subset of 

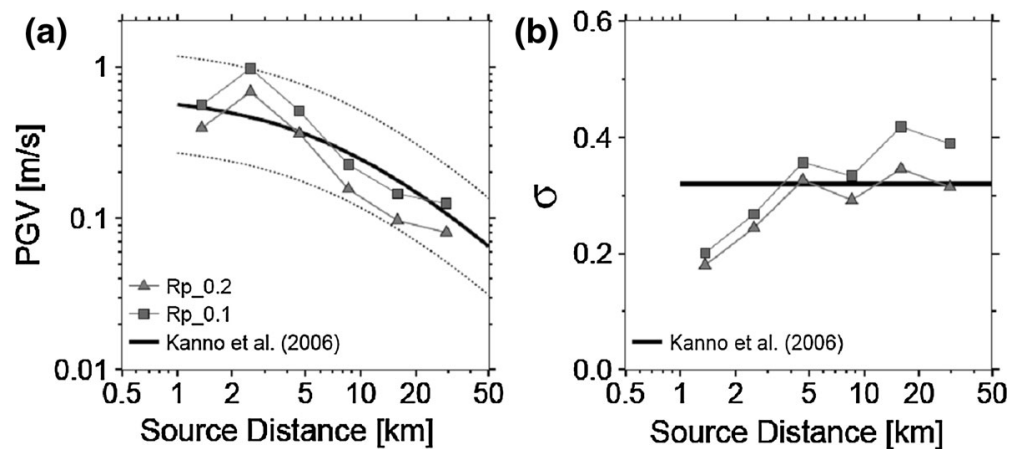

Fig. 17 Comparison of simulated mean horizontal PGV estimated for each $R_{p}$ value and the empirical attenuation relationship proposed by Kanno et al. (2006). a Mean PGVH values and b SD, where solid black lines represent the empirical mean curve ( $\pm \mathrm{SD}$, dashed black lines) and the empirical SD value, respectively. Results are plotted as a function to the source distance

parameters defined in the simulation (i.e., hypocenter location 2, 4 and 5, and all $V_{r}$-to- $V_{s}$ ratios). As in the previous subsection, purely unilateral ruptures (i.e., hypocenter 1 and 3 ) are not included in the statistics.

Figure 17a shows the mean PGVH values estimated by bin of source distances for $R_{p}=0.1 \mathrm{~W}$ and $R_{p}=0.2 \mathrm{~W}$. An increasing in $R_{p}$ decreases the simulated mean PGVH over the whole range of distances. In general, the synthetic mean curves are in good agreement with the empirical mean curve for all source distances. The simulated SD (Fig. $17 \mathrm{~b}$ ) is smaller than the empirical value, for distances less than $4 \mathrm{~km}$. In the case of $R_{p}=0.1 \mathrm{~W}$, there is observed a slight overestimation of the empirical value for distances larger than $4 \mathrm{~km}$, instead, for $R_{p}=0.2 \mathrm{~W}$, simulated SD is smaller or roughly equal to the empirical value.

Figure 18 presents isocontour maps for the simulated mean PGVH (Fig. 18a, c) and their SD estimates (Fig. 18b, d) associated with the maximum rise-time analyzed through $R_{p}$. A common spatial pattern, similar to the ones shown in previous scenarios analyzed, is observed near the SW area over the fault plane (Fig. 18a, c) and corresponds to the maximum mean PGVH values modeled. Simulated mean PGVH increases in the case $R_{p}=0.1 \mathrm{~W}$ with respect to $R_{p}=0.2 \mathrm{~W}$, and has a maximum value of about $1.6 \mathrm{~m} / \mathrm{s}$. The directivity has a minor effect in the spatial distribution of mean PGVH; isocontour lines are elongated along strike and have a symmetrical-like shape. The SD PGVH isocontour maps (Fig. 18b, d) also depict maximum deviations near the SW corner over the fault plane. Isocontour lines are elongated along strike but present asymmetrical shapes, and at the north and south fault ends appear lobes-like shapes.

Figure 19a shows the mean PGAH values and their associated SDs (Fig. 19b) estimated for each $R_{p}$ parameter and plotted as a function of source distance. These simulated values are compared against empirical curves proposed by Kanno et al. (2006). As shown in Fig. 19a, at close distances from the source $(R<3 \mathrm{~km})$, the simulated mean PGAH is in agreement with the mean empirical value, however, at larger distances the simulated values attenuate faster than empirical values. Instead, the simulated SD PGAH values are systematically below the empirical SD for all distances (Fig. 19b).

Figure 20a and c presents isocontour maps for the simulated mean PGAH and their SD estimates (Fig. 20b, d) computed for each $R_{p}$ value. The maximum mean PGAH values in each case (Fig. 20a, c) are located within the SW corner over the fault plane, but also large 
PGAH values are reached off the fault plane projection onto the surface and distributed along the strike and toward the fault trace. The latter observation is seen in both modeled cases, but is more evident when $R_{p}=0.1 \mathrm{~W}$. Simulated mean PGAH isocontour lines are elongated along strike and exhibit a symmetrical shape where none strong directivity effect is observed. The SD PGAH isocontour maps (Fig. 20b, d) present spatial distribution which is also N-S orientated, in the case of $R_{p}=0.1 W$ (Fig. 20b), the maximum SD is reached near the SW area over the fault plane, however, this pattern does not appear when $R_{p}=0.2 W$.

\section{Discussion}

We have documented seismological and tectonic evidences related to the San Ramón Fault System that have strong implications for any seismic hazard assessment and risk study for the Santiago Metropolitan area. The analyzed regional seismic catalog shows that the spatial distribution of the crustal seismicity is organized in an approximately $\mathrm{N}-\mathrm{S}$ direction, along two parallel strips. The western strip is well organized, homogenous and located
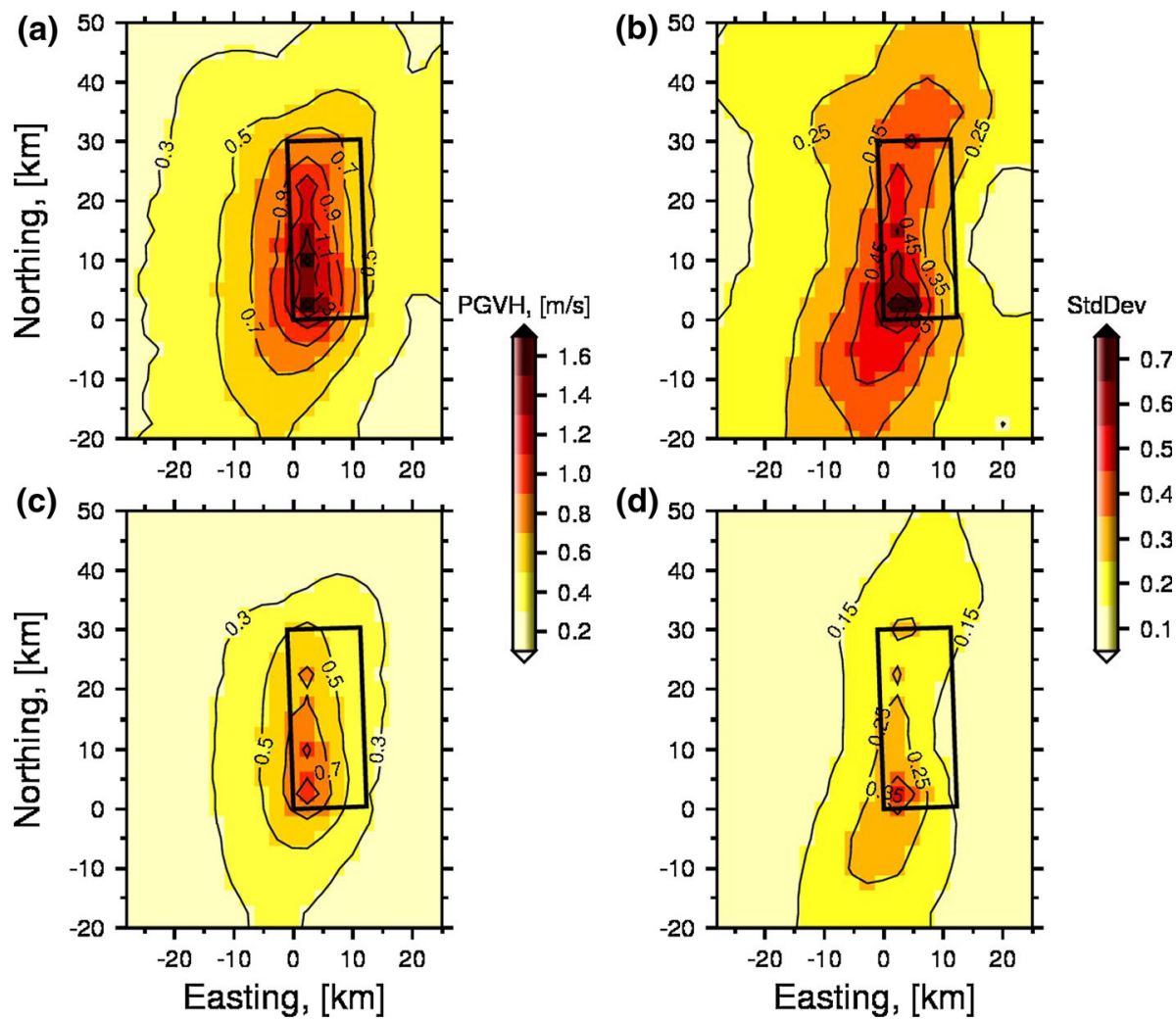

Fig. 18 Isocontour maps for PGVH computed for each $R_{p}$ value. Mean PGVH for a $R_{p}=0.1 W$, and c $R_{p}=0.2 W$. Their corresponding SD estimates are for $\mathbf{b} R_{p}=0.1 W$, and $\mathbf{d} R_{p}=0.2 W$. The black solid line rectangle corresponds to the San Ramón Fault projected to the surface 

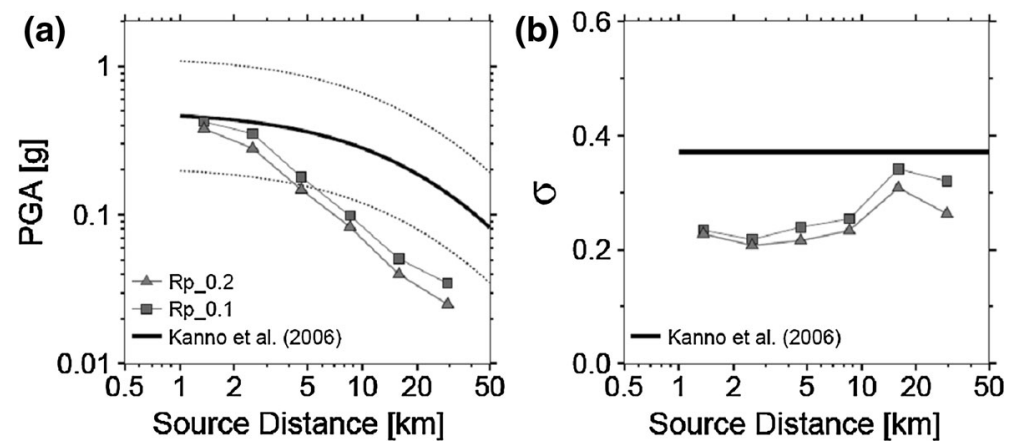

Fig. 19 Comparison of simulated mean horizontal PGA estimated for each $R_{p}$ value and the empirical attenuation relationship proposed by Kanno et al. (2006). a Mean PGAH values and b SD, where solid black lines represent the empirical mean curve ( $\pm \mathrm{SD}$, dashed black lines) and the empirical SD value, respectively. Results are plotted as a function to the source distance

(a)

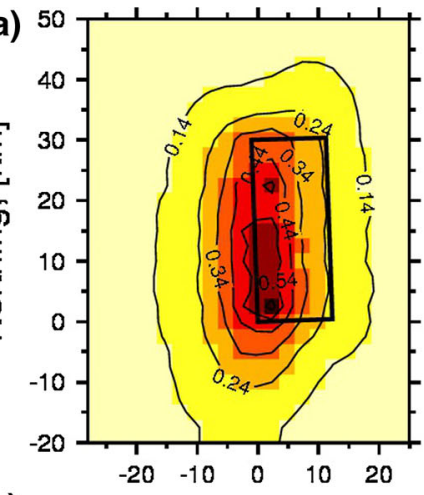

(c)
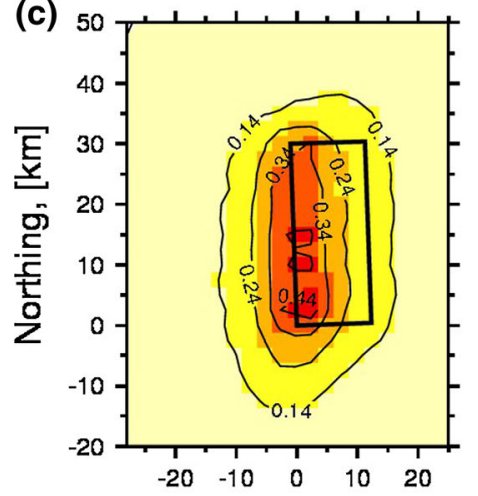

Easting, [km] (b)

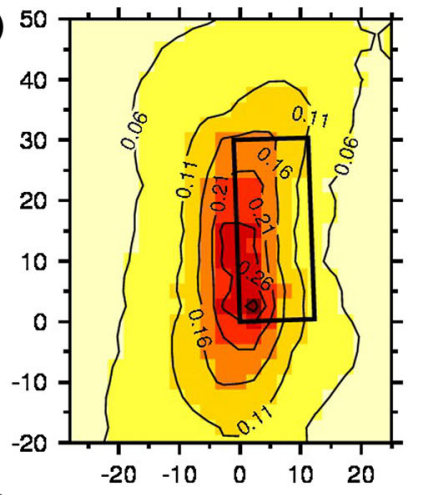

(d)

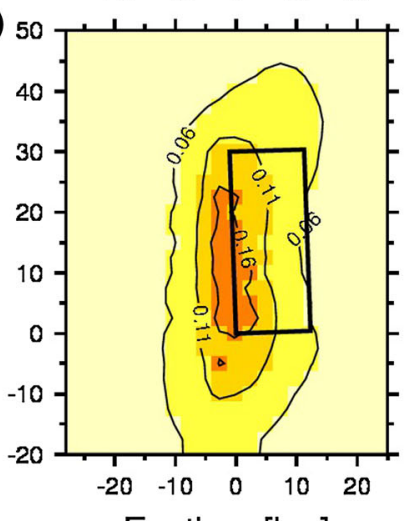

Easting, [km]

Fig. 20 Isocontour maps for PGAH computed for each $R_{p}$ value. Mean PGAH for a $R_{p}=0.1 W$, and c $R_{p}=0.2 \mathrm{~W}$. Their corresponding SD is for $\mathbf{b} R_{p}=0.1 \mathrm{~W}$, and $\mathbf{d} R_{p}=0.2 \mathrm{~W}$. The solid black line rectangle corresponds to the San Ramón Fault projected to the surface

directly on the first western front of the main Andes Cordillera, while the eastern strip is wider and more diffuse in terms of the spatial distribution and exhibits more shallow earthquakes with a greater concentration of events in the southern end (which in turn is 
located on the second topographic step determined by summit heights). Between both strips, disperse seismicity is observed with none clear pattern.

Several seismic events are located nearby or directly underneath some broadband seismological stations installed in the cordilleran region, among these, SJCH, FAR, LMEL, and YECH stations. From P-wave particle motion and S-P travel-time analysis done for each one of the events located underneath the stations, it was observed that the seismicity near Santiago and right under SJCH is clusterized around 9-13 km depth (8 of 13 events) and around $9 \mathrm{~km}$ depth at FAR. However, under $\mathrm{YECH}$, the seismicity pattern is more dispersed and varies between 6 and $13 \mathrm{~km}$ depth, and between 9 and $13 \mathrm{~km}$ depth under LMEL station.

Analysis performed on seismic waveform recordings for events located under the stations evidences similar signatures in their waveforms for events under SJCH and FAR, which is not as obvious as for events located under YECH and LMEL stations. The great and impressive waveform similarity observed for events located under SJCH and FAR stations indicates that brittle deformation is occurring there, that may be associated with a single type of seismic source rupture process. This reveals a common focal mechanism and the occurrence of events radiating exactly the same waveforms (the so-called "multiplets" or repeating earthquakes). Therefore, we associate this seismicity with the tectonic activity of the San Ramón Fault system at the west-vergent ramp that characterizes the fault geometry at about 9-10 km depth, according to the structural model proposed by Armijo et al. (2010). Even if these events are localized in a specific fault zone, small events were triggered there, so one can say from a seismological point of view, we are facing a seismically active fault. In that sense, the location and focal mechanisms of the seismicity reported here are similar to that observed from other thrust fault systems along convergent margins (Kao and Chen 2000; Rau et al. 2007).

Additionally, a point-source forward waveform modeling was made to search for a focal mechanism solution for a set of small earthquakes. It allowed us to verify the fault mechanism proposed by modeling the complete seismic wave field, and checking the fitting between synthetic and observed waveforms (P- and S-waves), for events located under some stations. Including P-wave particle motion analysis, it can be concluded that seismic events associated with SJCH and FAR stations are located at a depth of $9 \mathrm{~km}$, having basically the same focal mechanism (a reverse faulting running in an $\mathrm{N}-\mathrm{S}$ direction with a dip between $30^{\circ}$ and $40^{\circ}$, a rake of $100^{\circ}-120^{\circ}$, and S-P travel times of $1.2 \mathrm{~s}$ with very little dispersion). These observations agree in a coherent manner with the mechanical and geometrical features of the tectonic model proposed for this fault system (Armijo et al. 2010). The dispersion of epicenters and focal depths observed for events located under LMEL and YECH can be interpreted like the result of diffuse deformation in the Principal Cordillera and the variability of the waveforms to the diversity of focal mechanisms associated with brittle deformation in this zone.

We focused on characterizing the ground-motion variability in the vicinity of the San Ramón Fault by modeling several kinematic rupture scenarios for an $M_{w} 6.9$ earthquake by using a kinematic fractal $k^{-2}$ composite source model. The main goal was to examine the variability of ground-motion parameter and finite-source effects in the near-fault region, when changing physical kinematic source parameters. We compared numerically predicted ground-motion parameters with empirical predictive relationships proposed by Kanno et al. (2006). The statistical analysis focused on horizontal peak ground accelerations and velocities.

The mean PGVH simulated for different source parameters are, in general, in good agreement with the empirical mean values for all source distances; however, for some 
parameters and at large distances a slight underestimating was observed, which always keeps within the range of dispersion. In all modeled scenarios, an increase in the mean PGVH value is observed around $2 \mathrm{~km}$ of distance that can be associated with a directivity effect. A common spatial pattern (except in the hypocenter 1 case) is observed near the SW corner over the fault plane and corresponds to the maximum mean values of PGVH simulated that can be related to an effect of the slip direction on the fault which has a small component along strike.

Regarding the simulated SDs of PGVH for all modeled scenarios, we observed that the synthetic values at close distances are lower than the empirical SD. This tendency is modified, for instance, when considering different hypocenter locations, because those hypocenters that generate purely unilateral ruptures, the simulated mean PGVH slightly overestimates the empirical SD value at intermediate and large distances. Similar behavior occurs with the modeled SD values when varying the rupture velocity or the $R_{p}$ parameter, but in these cases, the overestimation is associated with greater source distances than for the prior cases.

With respect to PGAH statistical analysis, at close distances (less than $4 \mathrm{~km}$ ) the simulated mean PGAH agrees with the empirical mean values. At greater distances, the simulated mean PGAH attenuates faster than the empirical curve, which can be related, for instance, to the effects of oversimplification of wave propagation at high frequencies. A common spatial pattern in all statistical analysis (except for hypocenter 1, purely unilateral $\mathrm{S}-\mathrm{N}$ rupture) is that the maximum PGAH values are reached over the SW corner of the fault, effect that can be related to the fact that the slip direction over the fault has a small component along strike.

The synthetic PGAH SDs for all scenarios modeled fall systematically below the empirical SD value, which is always desirable when simulating ground-motion parameters. In particular, it is important in the scope of broadband strong ground-motion modeling because each new factor added to the modeling, such as site effect or path effect, could increase the uncertainties of the predicted ground-motion parameter.

In particular, including additional spatially heterogeneous rupture parameters, such as rupture velocity, stress drop, will introduce more variability/scatter on predicted groundmotion parameters and then increase SDs, but not necessarily a large increase on mean PGA at large distances when a statistical analysis is done. As initially stated, we focused on some specific source effects, then avoiding to explore additional effects on ground motions when including heterogeneities on other rupture source parameters. Certainly, it may be tested and properly included in further applications, and some work has been done under this perspective (e.g., Pulido et al. 2004; Pulido and Dalguer 2009 Graves and Pitarka 2010; Mena et al. 2010). Under the same perspective, in a recent work based on the same fractal kinematic $k^{-2}$ source model, where the constant stress-drop hypothesis at all scales was released, Ruiz et al. (2013) shown that the high frequency is greatly enhanced by combining both: (1) a larger average stress-drop value at small scales compared to the average values of larger subevents and (2) empirical Green's functions.

Based on the kinematic rupture scenarios simulated in this study, the maximum PGVH and PGAH values obtained in the different models coincide with the fact that these are always on the hanging wall of the San Ramón Fault, which is rather coherent with results from Chang et al. (2004). The overall results obtained here from kinematic rupture scenarios given an $M_{w} 6.9$ earthquake in the San Ramón Fault support the kinematic composite fractal $k^{-2}$ source model like a tool for ground-motion parameter prediction in the near-fault region. This is particularly true in the case of the simulated SDs. 
It is possible that faults breaking or rupturing close to the free surface produce seismic wave radiation that differ at the receivers, i.e., the high frequencies radiated from the most shallower areas differ from those located at deeper fault zones, which indicates that it is necessary to include some restrictions in the model. These differences can rise from complexities on the rupture process or on the radiated seismic wave. It is important to assess whether the deeper/shallower part of the fault, or the detachment ramp, will generate high-frequency waveforms. A large magnitude earthquake (around $M_{w} 7.4$ ) could be expected from a potential seismic event with surface rupture in the San Ramón Fault (Armijo et al. 2010), and thus a large magnitude scenario should be modeled. Additionally, further work must to be done in order to include more complexity into the fault geometry, for instance. A rupture breaking the free surface is another important element to keep in mind in order to improve future kinematic rupture scenarios for the target region. Indeed, further improvements of broadband strong ground motions should include local site/soil effects and basin/topographic effects. The latter can be incorporated through the propagation of low-frequency three-dimensional seismic waves, as done for instance in the Santiago basin (Pilz et al. 2011), or similarly in other areas, like Los Angeles basin in southern California, highly exposed to potential seismic hazard too (e.g., Olsen 2000; Mena et al. 2010; Graves and Pitarka 2010).

\section{Concluding remarks}

We have shown seismological and tectonic evidences related to the San Ramón Fault System that have undoubtedly strong implications for any seismic hazard assessment and risk study for the Santiago Metropolitan area.

Via a point-source forward waveform modeling, we verified the focal mechanisms proposed for a set of small earthquakes clustered under some stations, by checking the fitting between synthetic and observed waveforms (both P- and S-waves). Clustered seismic events associated with SJCH and FAR stations are located at a depth of 9-10 km, having similar focal mechanisms (reverse faulting running in an $\mathrm{N}-\mathrm{S}$ direction, dip in the range $30^{\circ}-40^{\circ}$, rake between $100^{\circ}$ and $120^{\circ}$, and S-P travel times of $1.2 \mathrm{~s}$ with little scatter). These events agree coherently with the structure and kinematics of the San Ramón Fault at crustal scale, proposed by Armijo et al. (2010). Events located under LMEL and YECH exhibit larger dispersion in the location of epicenters and focal depths that we interpret as diffuse deformation associated with the Principal Andes Cordillera. The waveforms variability agrees with the diversity of focal mechanisms, that we associate with brittle deformation.

The observed seismic activity clustered at about $10 \mathrm{~km}$ depth provides first evidence to support the seismically active character of the San Ramón Fault, implying a high-potential seismic hazard for the city of Santiago. Monitoring seismicity near this fault system will help to improve further seismic hazard assessment analysis in the region.

Results from kinematic rupture scenarios for an $M_{w} 6.9$ earthquake in the San Ramón Fault show that the maximum PGVH and PGAH mean values obtained from different rupture models always fall on the hanging wall of the structure, with expected maximum mean values in the order of $0.7-0.8 \mathrm{~g}$, which is consistent with hanging-wall effects observed in previous studies (e.g., Chang et al. 2004). Modeling near-fault broadband strong ground motions, in particular, in the vicinity of active faults are always critic to finite-source effects that are rather well simulated with the kinematic fractal $k^{-2}$ source model (Ruiz et al. 2011) used in this study. Directivity plays also an important role on 
ground-motion variability; our simulations suggest that small dextral component in the dominantly inverse San Ramón fault seems to have an effect on the mean PGAH and PGVH model results.

Acknowledgments We thank the National Seismological Service of the University of Chile for providing the earthquake catalog for the 2000-2011 period. Some figures were drawn using the Generic Mapping Tools (GMT) Version 4.1 (www.soest.hawaii.edu/gmt; Wessel and Smith 1998). We thank additional support from Millennium Nucleus on Seismotectonics and Seismic Hazard, International Earthquake Research Center, Montessus de Ballore (CIIT-MB), Grant P06-064-F, and CEGA (Andean Geothermal Center of Excelence) Fondap Project 15090013.

Open Access This article is distributed under the terms of the Creative Commons Attribution License which permits any use, distribution, and reproduction in any medium, provided the original author(s) and the source are credited.

\section{References}

Abrahamson NA, Silva WJ (1997) Empirical response spectral attenuation relations for shallow crustal earthquakes. Seismol Res Lett 68:94-128

Alvarado P, Barrientos S, Saez M, Astroza M, Beck S (2009) Source study and tectonic implications of the historic 1958 Las Melosas crustal earthquake, Chile, compared to earthquake damage. Phys Earth Planet Inter 175(1-2):26-36

Ambraseys NN, Simpson KA, Bommer JJ (1996) Prediction of horizontal response spectra in Europe. Earthq Eng Struct Dyn 25:371-400

Aochi H, Fukuyama E (2002) Three-dimensional nonplanar simulation of the 1992 Landers earthquake. J Geophys Res 107(B2). doi:10.1029/2000JB000061

Armijo R, Rauld R, Thiele R, Vargas G, Campos J, Lacassin R, Kausel E (2010) The West Andean Thrust, the San Ramón Fault, and the seismic hazard for Santiago, Chile. Tectonics 29(2):1-34. doi:10.1029/ 2008 TC002427

Astiz L, Kanamori H (1986) Interplate coupling and temporal variation of mechanisms of intermediate depth earthquakes in Chile. Bull Seismol Soc Am 76:1614-1622

Barrientos S, Plafker G, Lorca E (1992) Post-seismic coastal uplift in southern Chile. Geophys Res Lett 19:701-704

Barrientos S, Vera E, Alvarado P, Monfret T (2004) Crustal seismicity in central Chile. J S Am Earth Sci 16:759-768

Ben-Menahem A (1961) Radiation of seismic surface-waves from finite moving sources. Bull Seismol Soc Am 51:401-435

Berge C, Gariel J-C, Bernard P (1998) A very broad-band stochastic source model used for near source strong motion prediction. Geophys Res Lett 25(7):1063-1066

Bernard P, Herrero A, Berge-Thierry C (1996) Modeling directivity of heterogeneous earthquakes ruptures. Bull Seismol Soc Am 86:1149-1160

Boore DM, Joyner WB, Fumal TE (1997) Equations for estimating horizontal response spectra and peak acceleration from western North American earthquakes: a summary of recent work. Seismol Res Lett 68:128-153

Bouchon M (1981) A simple method to calculate Green's functions for elastic layered media. Bull Seismol Soc Am 71(4):959-971

Bouchon M, Aki K (1977) Discrete wavenumber representation of seismic-sources wave fields. Bull Seismol Soc Am 67:259-277

Campos J, Kausel E (1990) The large 1939 intraplate earthquake of southern Chile. Seismol Res Lett 61(1):43

Chang T, Cotton F, Tsai Y, Angelier J (2004) Quantification of hanging-wall effects on ground motion: some insights from the 1999 Chi-Chi earthquake. Bull Seismol Soc Am 94(6):2186-2197

Charrier R, Baeza O, Elgueta S, Flynn JJ, Gana P, Kay SM, Muñoz N, Wyss AR, Zurita E (2002) Evidence for Cenozoic extensional basin development and tectonic inversion south of the flat-slab segment, southern Central Andes, Chile ( $\left.33^{\circ}-36^{\circ} \mathrm{S}\right)$. J S Am Earth Sci 15(1):117-139 
Charrier R, Bustamante M, Comte D, Elgueta E, Flynn J, Iturra I, Muñoz N, Pardo M, Thiele R, Wyss A (2005) The Abanico extensional basin: regional extension, chronology of tectonic inversion, and relation to shallow seismic activity and Andean uplift. Neues Jahrbuch für Geologie und Paläontologie, Abh 236(1-2):43-77

Cifuentes IL (1989) The 1960 Chilean earthquakes. J Geophys Res 94:665-680

Convertito V, Emolo A, Zollo A (2006) Seismic-hazard assessment for a characteristic earthquake scenario: an integrated probabilistic-deterministic method. Bull Seismol Soc Am 96(2):377-391

Cotton F, Campillo M (1995) Frequency domain inversion of strong motions : application to the 1992 Landers earthquake. J Geophys Res 100:3961-3975

Coutant O (1990) Programme de Simulation Numérique AXITRA. Rapport LGIT, Université Joseph Fourier, Grenoble

Cultrera G, Cirella A, Spagnuolo E, Herrero A, Tinti E, Pacor F (2010) Variability of kinematic source parameters and its implication on the choice of the design scenario. Bull Seismol Soc Am 100:941-953. doi:10.1785/0120090044

Demets C, Gordon RG, Argus DF, Stein S (1994) Effect of recent revisions to the geomagnetic reversal time-scale on estimates of current plate motions. Geophys Res Lett 21(20):2191-2194

Farías M, Comte D, Charrier R, Martinod J, David C, Tassara A, Tapia F, Fock A (2010) Crustal-scale structural architecture in central Chile based on seismicity and surface geology: implications for Andean mountain building. Tectonics 29(3):TC3006

Farías M, Comte D, Roecker S, Carrizo D, Pardo M (2011) Crustal extensional faulting triggered by the 2010 Chilean earthquake: the Pichilemu seismic sequence. Tectonics 30:TC6010. doi:10.1029/ 2011 TC002888

Graves RW, Pitarka A (2010) Broadband ground-motion simulation using a hybrid approach. Bull Seismol Soc Am 100(5A):2095-2123. doi:10.1785/0120100057

Haskell NA (1964) Total energy and energy spectral density of elastic wave radiation from propagating faults. Bull Seismol Soc Am 54:1811-1842

Kanno T, Narita A, Morikawa M, Fujiwara H, Fukushima Y (2006) A new attenuation relation for strong ground motion in Japan based on recorded data. Bull Seismol Soc Am 96(3):879-897. doi:10.1785/ 0120050138

Kao H, Chen WP (2000) The Chi-Chi earthquake sequence: active, out-of-sequence thrust faulting in Taiwan. Science 288:2346-2349

Kissling E, Kradolfer U, Maurer H (1995) VELEST user's guide-short introduction. Institute of Geophysics and Swiss Seismological Service, ETH Zürich, Switzerland

Kjartansson E (1979) Constant Q-wave propagation and attenuation. J Geophys Res 84(B9):4737-4748. doi:10.1029/JB084iB09p04737

Lay T, Ammon CJ, Kanamori H, Koper KD, Sufri O, Hutko AR (2010) Teleseismic inversion for rupture process of the 27 February 2010 Chile (Mw 8.8) earthquake. Geophys Res Lett 37:L13301. doi:10. 1029/2010GL043379

Legrand D, Delouis B, Dorbath L, David C, Campos J, Marquez L, Thompson J, Comte D (2007) Source parameters of the $\mathrm{M}_{\mathrm{w}}=6.3$ Aroma crustal earthquake of July 24, 2001 (northern Chile), and its aftershock sequence. J S Am Earth Sci 24(1):58-68

Leyton F, Ruiz S, Sepúlveda S (2010) Reevaluación del peligro sísmico probabilístico en Chile central. Andean Geol 37(2):455-472

Lomnitz C (2004) Major earthquakes of Chile: a historical survey, 1535-196. Seismol Res Lett 75:368-378

Madariaga R, Métois M, Vigny C, Campos J (2010) Central Chile finally breaks. Science 328(5975):181-182

Mai PM, Beroza GC (2003) A hybrid method for calculating near source broadband seismograms: application to strong motion prediction. Phys Earth Planet Inter 137:183-199

Mena B, Mai PM, Olsen KB, Purvance MD, Brune JN (2010) Hybrid broadband ground-motion simulation using scattering Green's functions: application to large-magnitude events. Bull Seismol Soc Am 100(5):2143-2162. doi:10.1785/0120080318

Oglesby DD, Day SM (2001) The effect of fault geometry on the 1999 Chi-Chi (Taiwan) earthquake. Geophys Res Lett 28(9):1831-1834

Olsen KB (2000) Site amplification in the Los Angeles basin from 3D modeling of ground motion. Bull Seismol Soc Am 90:S77-S94

Pilz M, Parolai S, Stupazzini M, Paolucci R, Zschau J (2011) Modelling basin effects on earthquake ground motion in the Santiago de Chile basin by a spectral element code. Geophys J Int 187:929-945. doi:10. 1111/j.1365-246X.2011.05183.x

Plafker G, Savage JC (1970) Mechanism of the Chilean earthquake of May 21 and 22, 1960. Geol Soc Am Bull 81:1001-1030 
Pulido N, Dalguer L (2009) Estimation of the high-frequency radiation of the 2000 Tottori (Japan) earthquake based on a dynamic model of fault rupture: application to the strong ground motion simulation. Bull Seismol Soc Am 99(4):2305-2322. doi:10.1785/012008016

Pulido N, Ojeda A, Kuvvet A, Kubo T (2004) Strong ground motion estimation in the Marmara sea region (Turkey) based on a scenario earthquake. Tectonophysics 391:357-374

Raghu Kanth STG, Dash SK (2010) Deterministic seismic scenarios for North East India. J Seismol 14:143-167. doi:10.1007/s10950-009-9158-y

Rau R-J, Chen KH, Ching K-E (2007) Repeating earthquakes and seismic potential along the northern Longitudinal Valley fault of eastern Taiwan. Geophys Res Lett 34:L24301. doi:10.1029/ 2007GL031622

Rauld R (2011) Deformación cortical y peligro sísmico asociado a la falla San Ramón en el frente cordillerano de Santiago, Chile central $\left(33^{\circ} \mathrm{S}\right)$, Tesis para optar al grado de Doctor en Ciencias mención Geología, Universidad de Chile, Santiago

Ruiz J, Baumont D, Bernard P, Berge-Thierry C (2007) New approach in the kinematic $\mathrm{k}^{-2}$ source model for generating physical slip velocity functions. Geophys J Int 171:739-754. doi:10.1111/j.1365-246X. 2007.03503.x

Ruiz JA, Baumont D, Bernard P, Berge-Thierry C (2011) Modelling directivity of strong ground motion with a fractal, $\mathrm{k}^{-2}$, kinematic source model. Geophys J Int 186(1):226-244. doi:10.1111/j.1365-246X. 2011.05000.x

Ruiz JA, Baumont D, Bernard P, Berge-Thierry C (2013) Combining a kinematic fractal source model with hybrid Green's functions to model broadband strong ground motion. Bull Seismol Soc Am 103:6. doi:10.1785/0120110135

Ryder I, Rietbrock A, Kelson K, Burgmann R, Floyd M, Socquet A, Vigny C, Carrizo D (2012) Large extensional aftershocks in the continental forearc triggered by the 2010 Maule earthquake, Chile. Geophys J Int 188:879-890. doi:10.1111/j.1365-246X.2011.05321.x

Sabetta F, Pugliese A (1987) Attenuation of peak horizontal acceleration and velocity from Italian strongground records. Bull Seismol Soc Am 77:1491-1513

Sepulveda SA, Astroza M, Kausel E, Campos J, Casas EA, Rebolledo S, Verdugo R (2008) New findings on the 1958 Las Melosas earthquake sequence, central Chile: implications for seismic hazard related to shallow crustal earthquakes in subduction zones. J Earthq Eng 12(3):432-455

Thiele R (1980) Geología de la hoja Santiago, Región Metropolitana. Carta Geológica de Chile, escala 1:250.000. Instituto de Investigaciones Geológicas, Santiago, No 39, pp 1-51

Vigny C, Rudolff A, Ruegg J-C, Madariaga R, Campos J, Alvarez M (2009) Upper plate deformation measured by GPS in the Coquimbo Gap, Chile. Phys Earth Planet Inter 175(1-2):86-95

Vigny C, Socquet A, Peyrat S, Ruegg J-C, Métois M, Madariaga R, Morvan S, Lancieri M, Lacassin R, Campos J, Carrizo D, Bejar-Pizarro M, Barrientos S, Armijo R, Aranda C, Valderas-Bermejo M-C, Ortega I, Bondoux F, Baize S, Lyon-Caen H, Pavez A, Vilotte J-P, Bevis M, Brooks B, Smalley R, Parra H, Baez J-C, Blanco M, Cimbaro S, Kendrick E (2011) The 2010 Mw 8.8 Maule megathrust earthquake of central Chile, monitored by GPS. Science 332:1417. doi:10.1126/science.1204132

Vita-Finzi C, Mann CD (1994) Seismic folding in coastal south central Chile. J Geophys Res 99:12289-12290

Wald DJ, Heaton TH (1994) Spatial and temporal distribution of slip for the 1992 Landers, California earthquake. Bull Seismol Soc Am 84:668-691

Wald DJ, Heaton TH, Hudnut KW (1996) A dislocation model of the 1994 Northridge, California earthquake determined from strong-motion, GPS, and leveling-line data. Bull Seismol Soc Am 86:S39-S70

Wessel P, Smith WHF (1998) New, improved version of generic mapping tools released. EOS Trans Am Geophys Union 79(47):579 